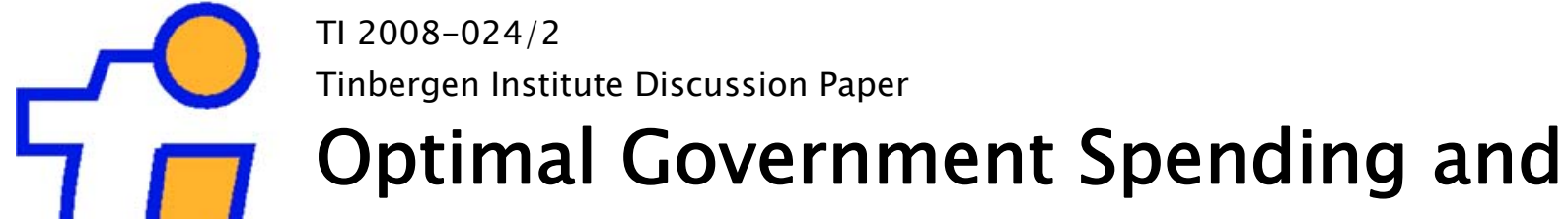 Unemployment
}

\author{
Ludger Linnemann \\ Andreas Schabert ${ }^{2}$
}

' University of Bonn;

2 University of Dortmund. 


\section{Tinbergen Institute}

The Tinbergen Institute is the institute for economic research of the Erasmus Universiteit Rotterdam, Universiteit van Amsterdam, and Vrije Universiteit Amsterdam.

Tinbergen Institute Amsterdam

Roetersstraat 31

1018 WB Amsterdam

The Netherlands

Tel.: $\quad+31(0) 205513500$

Fax: $\quad+31(0) 205513555$

Tinbergen Institute Rotterdam

Burg. Oudlaan 50

3062 PA Rotterdam

The Netherlands

Tel.: $\quad+31(0) 104088900$

Fax: $\quad+31(0) 104089031$

Most TI discussion papers can be downloaded at http:/ /www.tinbergen.nl. 


\title{
Optimal government spending and unemployment
}

\author{
Ludger Linnemann ${ }^{1}$ \\ University of Bonn \\ Andreas Schabert \\ University of Dortmund and Tinbergen Institute
}

This version: February 29, 2008

JEL classification: E62, E32

Keywords: Optimal fiscal policy; government spending; labor market frictions; unemployment; stabilization policy.

Abstract: We study optimal government spending in a business cycle model with frictional unemployment. The Ramsey optimal policy is contrasted with a reference policy which would be first best in a frictionless economy. Results are: the Ramsey policy i) implies a higher steady state ratio of government spending to private consumption than the reference policy; ii) is procyclical under technology shocks and countercyclical under demand shocks (while the public spending ratio to private consumption is always countercyclical); iii) stabilizes employment, in some cases even at the cost of higher consumption volatility; iv) is qualitatively unaltered in a sticky price version with jointly optimal monetary and fiscal policy.

\footnotetext{
${ }^{1}$ Corresponding author. University of Bonn, Department of Economics, Adenauerallee 24-42, D-53113 Bonn, Germany, email: ludger.linnemann@uni-bonn.de, tel: +49/228/734073.
} 



\section{Introduction}

In this paper, we analyze the Ramsey - optimal time path of useful government spending in a business cycle model with labor market frictions. The question how government spending should be adjusted in response to cyclical conditions has received more interest in policy debates rather than in theoretical work. One of the reasons may be that in standard real business cycle models government spending and private consumption should typically be aligned according to the marginal utilities they provide, such that government spending is procyclical. ${ }^{1}$ The public policy debate, in contrast, concentrates on the possible use of countercyclical spending policy. There is thus a significant mismatch between theoretical and policy discussions.

However, we argue that the optimal intertemporal allocation of government spending is significantly different from what it would be in a first best world if the policy maker acts as a Ramsey planner in an economy that exhibits frictional unemployment. We extend the literature on unemployment due to search and matching frictions (see Mortensen and Pissarides, 1994, Merz, 1995, Andolfatto, 1995) by including useful government spending chosen benevolently. ${ }^{2}$ There is a hiring externality that makes employment inefficiently low, as in Blanchard and Gali (2006). Employment is a state variable, hiring costs that are due to frictions on the labor market make employment reallocations costly, and wages are determined by a Nash bargain. The economy is hit by technology shocks and shocks to consumption demand. The government has access to lump-sum taxes, which allows to abstract from the role of public finance in order to concentrate on the dynamic properties of government spending. Thus, our analysis can be viewed as complementary to recent studies on dynamic optimal taxation in economies labor market frictions (see Domeij, 2005, or Arseneau and Chugh, 2007) who extend Chari et al.'s (1994) benchmark analysis of optimal taxation for exogenously given government expenditures.

The Ramsey optimal policy in this model has the following properties: On the one hand, the policy maker aims at distributing resources in an efficient way. Since government spending appears in the utility function, this amounts to keeping the marginal utilities of private consumption and government spending aligned, as they would be under the first best allocation. On the other hand, since employment reallocations are costly, there is an incentive to stabilize employment when the economy is hit by shocks. The Ramsey optimal policy that we study can be understood as a solution to this policy trade-off between optimal public goods provision and optimal employment stabilization.

The main results are as follows. Regarding the long-run, we compare the steady state

\footnotetext{
${ }^{1}$ For a seminal analysis of government expenditures in real business cycle models, see Baxter and King (1993).

${ }^{2}$ The assumption that government spending enters private utility functions is made to motivate the existence of strictly positive fiscal spending in the first place. An alternative formulation, where the same goal is achieved by letting government spending enter private production functions, yields qualitatively similar results.
} 
under the Ramsey policy with a reference policy that would be the first best policy in a frictionless version of the model without shocks; given our parameter choices, this reference policy just fixes the ratio of government spending to private consumption to an exogenous utility parameter. The result of the comparison is that for the same parameter values the Ramsey policy steady state entails a higher ratio of government spending to private consumption (composed of higher government spending and lower consumption), along with higher employment. The reason is the presence of the hiring externality that makes employment inefficiently low. By raising government spending above the level that would be advisable under the reference policy, employment is increased, and although private consumption is reduced due to the higher resource withdrawal from the private sector, the overall result is superior in welfare terms. The mechanism is that the Ramsey policy uses high fiscal spending in order to restrain consumption; this lowers the reservation wage (the marginal rate of substitution between consumption and leisure), and hence allows employment to increase, thereby achieving the optimal (second best) level.

We then turn to the dynamic analysis and study optimal responses to exogenous technology and demand shocks. If the economy experiences an adverse technology shock, the optimal policy reaction is to let employment, consumption, and government spending decline; fiscal policy is thus procyclical. This would also be the optimal outcome in an RBC model without employment frictions (see e.g. Lansing, 1997). In our environment with employment frictions, government spending under the Ramsey policy is less procyclical than under the reference policy. Consequently, employment adjustments are mitigated under the Ramsey policy and government expenditures are adjusted in the short run to stabilize employment. If the economy is hit by an adverse demand shock, i.e. by an exogenously induced temporary reduction in private consumption, things are different. The Ramsey policy response is countercyclical in this case, with government spending increasing whereas consumption and employment decline. The reference policy would decrease spending in this case. However, in our model the rise in government spending mitigates the employment decrease. In this case, hence, optimal policy can indeed be described as a countercyclical fiscal policy that stabilizes employment fluctuations. While this result has a Keynesian ring to it, obviously, it is based entirely on the logic of minimizing the distortions arising from the frictions embedded in the model.

Finally, we consider jointly optimal fiscal and monetary policies in a model version with sticky prices. The reason for studying this extension is that, traditionally, stabilization policy is often thought to be the realm of monetary, not fiscal policy. Monetary stabilization policy has been extensively studied in the New Keynesian literature (e.g. Clarida et al., 1999, Woodford, 2003). The central result is that monetary policy should stabilize the price level, which - if there are no 'cost-push' type shocks - also implies a stabilization of the welfare relevant output gap. The implication is that fluctuations that occur as under flexible prices are not detrimental to welfare. However, in a model 
with labor market frictions stabilizing prices might not be optimal anymore, in particular when, additionally, the rigidity of real wages is assumed (see Blanchard and Gali, 2006; for other New Keynesian models with labor frictions see Krause and Lubik, 2007, Gertler and Trigari, 2006, or Faia, 2007). None of these papers discusses the possible role fiscal policy, which is the center of our analysis in this paper.

Previous papers analyzing optimal fiscal policy in sticky price models either study dynamic optimal distortionary taxation problems with given exogenous government expenditures (see Schmitt-Grohe and Uribe, 2004, and Benigno and Woodford, 2003), or concentrate on the case where monetary policy is unable to fulfill its stabilization task in a currency union, since it cannot react appropriately to idiosyncratic shocks on the level of the member countries (see Beetsma and Jensen 2005, Gali and Monacelli, 2006). Thus, the result of this literature is a policy assignment where monetary policy is charged with stabilizing the economy, and fiscal policy only comes into play if some extraneous reason impedes monetary stabilization.

In contrast, in the present paper we show that the optimal policy assignment should be such that fiscal policy has a role as a stabilization device even alongside an optimal monetary policy in a New Keynesian sticky price model. This is true in our model because the existence of labor frictions adds a second distortion (on top of the usual New Keynesian distortion due to pricing frictions) that optimal policy has to consider. We study the jointly Ramsey-optimal fiscal and monetary policy and find a simple policy assignment: while monetary policy keeps the price level practically constant, fiscal policy continues to use government spending in qualitatively the same way as in the flexible price version of the model (where monetary policy did not play any role) ${ }^{3}$. This means that even in a closed economy with a fully functional optimizing monetary policy fiscal policy has a role in stabilizing employment, using pro- or countercyclical variations in spending depending on the type of shock hitting the economy. Thus, intuitively, monetary policy appears to take care of the nominal distortions, and fiscal policy of the real ones.

The paper is organized as follows. Section 2 develops the model. In section 3 the Ramsey optimal policy and a reference policy are described. Section 4 presents long-run and short-run results. In section 5 the analysis is extended to the case of imperfectly flexible prices. Section 6 concludes.

\section{The model}

We analyze a dynamic general equilibrium model in which households accumulate capital and supply labor. Fiscal policy decides on the level of government spending, which is financed by a lump-sum tax and provides utility to households. There is a friction in

\footnotetext{
${ }^{3}$ That monetary policy is absent from the flexible price version of the model is due to the abstraction from money demand distortions.
} 
the labor market which consists of the fact that hiring of labor by firms is costly. The labor market part is modelled as in Blanchard and Gali (2006). Our model differs from theirs in that we also consider capital accumulation and, most importantly, concentrate on fiscal, not monetary policies, assuming flexible prices. However, the robustness of our results with respect to introducing price stickiness and a separate role for monetary policy is analyzed in section 5 .

Let $s_{t}$ denote the state realized at date $t \geq 0$ and let $s^{t}$ denote a particular history of states from period 0 to $t, s^{t}=\left\{s_{t}, s_{t-1}, \ldots, s_{0}\right\}$, where $S: s_{t} \in S$ is the set of possible states and $S^{t}$ the set of possible histories. Further, let $\pi\left(s^{t} \mid s^{t-1}\right)$ be the period $(t-1)$ probability of the occurrence of the history $s^{t}$, and $\pi\left(s^{t}\right)=\pi\left(s^{t} \mid s_{0}\right)$ its unconditional probability, where $s_{0}$ is the initial state with $\pi\left(s_{0}\right)=1$. Throughout the paper, we economize on notation by leaving out the reference to the state $s^{t}$ wherever possible without risk of confusion.

\subsection{Households}

There is a representative household consisting of a continuum of members (indexed with $j$ ), normalized to measure one. The household members' preferences are identical, but members may differ with regard to their employment status. Let $n_{t} \in(0,1)$ denote the fraction of employed household members. These work the fixed amount of one time unit per period and earn a real wage $w_{t}$. Employment reduces leisure and utility by a fixed amount $\chi>0$. Expected lifetime utility of the household is then given by $\sum_{t=0}^{\infty} \sum_{s^{t} \in S^{t}} \pi\left(s^{t}\right) \beta^{t}\left\{\int_{0}^{1}\left[u\left(c_{j t}\left(s^{t}\right)\right)+v\left(g_{t}\left(s^{t}\right)\right)\right] d j-\int_{0}^{n\left(s^{t}\right)} \chi d j\right\}$, which can be rewritten as

$$
E_{0} \sum_{t=0}^{\infty} \beta^{t}\left\{\int_{0}^{1}\left[u\left(c_{j t}\right)+v\left(g_{t}\right)\right] d j-\int_{0}^{n_{t}} \chi d j\right\}, \quad \beta \in(0,1),
$$

where $E_{0}$ is the expectations operator contingent on the information in period $0, c_{j t}$ is private consumption of the $j$-th member, and $g_{t}$ is government spending which produces nonrival public goods that are consumed by all household members in the same amount; the functions $u\left(c_{j t}\right)$ and $v\left(g_{j t}\right)$ are assumed to be increasing, twice continuously differentiable, and concave.

All household members have access to a perfect capital market where a complete set of one period contingent claims is traded. The reason for assuming perfect capital markets is to avoid differences in asset holdings and consumption levels among household members; thus, heterogeneity refers to the employment status only (like in Merz, 1995, and a large subsequent literature).

In each period $t$ household members trade claims to period $t+1$, whose payment is contingent on the realization of $s_{t+1}$. Let $Q_{t, t+1}\left(s^{t}, s_{t+1}\right)$ be the period-t-price of one unit of the consumption good in a particular state $s^{t+1}$ in period $t+1$. When the $j$ th household member's portfolio of state contingent claims yields a random payment 
$m_{j t+1}\left(s^{t}, s_{t+1}\right)$ in period $t+1$, then the period $t$ price of a random payoff is given by $\sum_{s_{t+1} \in S} Q_{t, t+1}\left(s^{t}, s_{t+1}\right) m_{j t+1}\left(s^{t}, s_{t+1}\right)=E_{t}\left[\phi_{t, t+1} m_{j t+1}\right]$, where $m_{j t+1}=m_{j t+1}\left(s^{t}, s_{t+1}\right)$ and $\phi_{t, t+1}=Q_{t, t+1}\left(s^{t}, s_{t+1}\right) / \pi\left(s^{t+1} \mid s^{t}\right)$ is the stochastic discount factor.

Households can further invest in physical capital and receive profits $q_{j t}$ from firms, which they own (share holdings are not explicitly modelled, for simplicity). The household's flow budget constraint can then be written as

$$
\int_{0}^{1} E_{t}\left[\phi_{t, t+1} m_{j t+1}\right] d j \leq \int_{0}^{1}\left(m_{j t}-c_{j t}-i_{j t}+\tau_{j t}+r_{t} k_{j t-1}\right) d j+\int_{0}^{n_{t}} w_{t} d j+q_{j t}
$$

where $i_{j t}$ is investment in physical capital $k_{j t}$, earning a real return $r_{t}$ when lent out to the firm sector for one period, and $\tau_{j t}$ denotes real lump-sum tax payments. Capital is accumulated according to

$$
k_{j t}=(1-\delta) k_{j t-1}+i_{j t}
$$

where $\delta \in(0,1)$ is a fixed depreciation rate. Maximizing expected lifetime utility of the household subject to the budget constraint (2) and (3), as well as to a no-Ponzi-game condition $\lim _{t \rightarrow \infty} E_{0}\left[\phi_{0, t} m_{j t+1}\right] \geq 0$ and a non-negativity condition for capital for given initial values $k_{j,-1}$ and $m_{j 0}$, leads to the following first order conditions for consumption and investment in contingent claims and in physical capital ${ }^{4}$ :

$$
\begin{aligned}
u_{c}\left(c_{j t}\right) & =\Lambda_{t}, \\
\phi_{t, t+1} & =\beta \frac{\Lambda_{t+1}}{\Lambda_{t}}, \\
\Lambda_{t} & =\beta E_{t} \Lambda_{t+1}\left[r_{t+1}+1-\delta\right],
\end{aligned}
$$

and transversality conditions $\lim _{t \rightarrow \infty} \beta^{t} E_{0} \Lambda_{t} k_{j t}=0$ and $\lim _{t \rightarrow \infty} \beta^{t} E_{0} \Lambda_{t} m_{j t+1}=0$, where $\Lambda_{t}$ is the multiplier on the flow budget (2). As a consequence, all household members $h \neq j$ exhibit an identical marginal utility of consumption $u_{c}\left(c_{h t}\right)=u_{c}\left(c_{j t}\right)=\Lambda_{t}$.

We further assume that preferences exhibit constant relative risk aversion and that utility from consumption is affected by an exogenous stochastic common random preference shifter $\Omega_{t}$ (which will serve as our "demand shock"):

$$
u\left(c_{j t}\right)=\Omega_{t} \frac{c_{j t}^{1-\sigma}}{1-\sigma} \text { and } \quad v\left(g_{t}\right)=\varphi \frac{g_{t}^{1-\gamma}}{1-\gamma}, \quad \sigma, \varphi, \gamma>0
$$

where $\Omega_{t}=\rho_{d} \Omega_{t-1}+\left(1-\rho_{d}\right) \Omega+\varepsilon_{t}^{d}, \rho_{d} \in(0,1), E_{t} \varepsilon_{t+1}^{d}=0$ and the constant steady state level is $\Omega=1$ (throughout, we denote steady state values by symbols without a time subscript). Given that consumption of each household member then satisfies $c_{j t}=$ $\left(\Omega_{t} / \Lambda_{t}\right)^{1 / \sigma}$, we can rewrite the first order conditions in terms of aggregate household

\footnotetext{
${ }^{4}$ We assume that the all agents perceive the law of motion for the aggregate state to follow a first order Markov process.
} 
consumption,

$$
\begin{aligned}
\phi_{t, t+1} & =\beta \frac{\Omega_{t+1} c_{t+1}^{-\sigma}}{\Omega_{t} c_{t}^{-\sigma}}, \\
\Omega_{t} c_{t}^{-\sigma} & =\beta E_{t} \Omega_{t+1} c_{t+1}^{-\sigma}\left[r_{t+1}+1-\delta\right]
\end{aligned}
$$

where $c_{t}$ denotes aggregate household consumption satisfying $c_{t}=\int_{0}^{1} c_{j t} d j$ and $c_{t}=$ $c_{j t}$ for all $j$. Furthermore the transversality conditions $\lim _{t \rightarrow \infty} E_{0} \beta^{t} \Omega_{t} c_{t}^{-\sigma} k_{t}=0$ and $\lim _{t \rightarrow \infty} E_{0} \beta^{t} \Omega_{t} c_{t}^{-\sigma} m_{t+1}=0$, where $m_{t}=\int_{0}^{1} m_{j t} d j$ and $k_{t}=\int_{0}^{1} k_{j t} d j$, have to hold.

\section{$2.2 \quad$ Firms}

We model firms as being monopolistically competitive in order to be able to introduce price stickiness later. Thus, assume that there is a perfectly competitive aggregation sector that purchases a continuum of individual intermediate output goods $y_{i t}$ indexed on $i \in[0,1]$ nominal prices $P_{i t}$ to produce aggregate output $y_{t}$ with the technology

$$
y_{t}=\left(\int_{0}^{1} y_{i t^{\frac{\varepsilon-1}{\varepsilon}}} d i\right)^{\frac{\varepsilon}{\varepsilon-1}}, \quad \varepsilon>1 .
$$

As a result, the demand for each product is $y_{i t}=\left(\frac{P_{i t}}{P_{t}}\right)^{-\varepsilon} y_{t}$, where $P_{t}$ is the general price level satisfying $P_{t}^{1-\varepsilon}=\int P_{i t}^{1-\varepsilon} d i$. Each intermediate good is produced by a single monopolistically competitive firm. The $i$-th firm's technology is

$$
y_{i t}=a_{t} n_{i t}^{v} k_{i t-1}^{1-v}, \quad v \in(0,1)
$$

where $a_{t}$ is stochastic level of productivity satisfying $a_{t}=\rho_{a} a_{t-1}+\left(1-\rho_{a}\right) a+\varepsilon_{t}^{a}, \rho_{a} \in(0,1)$, where $E_{t-1} \varepsilon_{t}^{a}=0$ holds for the innovation, and the constant is $a=1$.

Following Blanchard and Gali (2006), firms can hire instantaneously, but hires $h_{i t}$ are associated with costs $z_{t}$ per hire (assumed to be the same for all firms). The costs per hire, which are taken as given by each individual firm, are assumed to be increasing and convex in the level of aggregate labor market tightness $x_{t}$,

$$
z_{t}=b x_{t}^{\alpha}, \quad \alpha, b>0
$$

where tightness is defined as the ratio of aggregate hires $h_{t}=\int h_{i t} d i$ to the number of unemployed at the beginning of the period $u_{t}$,

$$
x_{t}=h_{t} / u_{t} \in[0,1] .
$$

Thus, $x_{t}$ can be interpreted as a job finding rate. Further, allowing for separation in each 
period, the number of worker in each firm evolves according to

$$
n_{i t}=(1-d) n_{i t-1}+h_{i t}
$$

where $d \in(0,1)$ is the exogenous separation rate. Thus, the total amount of hires satisfies:

$$
h_{t}=n_{t}-(1-d) n_{t-1},
$$

where $n_{t}=\int n_{i t} d i$ denotes the number of employed. Accordingly, the beginning-of-period (before hiring) measure of unemployment $u_{t}$ satisfies: $u_{t}=1-(1-d) n_{t-1}$, while unemployment after hiring is given by $1-n_{t}$.

An intermediate good producing firm $i$ is assumed to maximize the expected discounted sum of real period profits $q_{i t}$,

$$
\begin{aligned}
\max E_{t} \sum_{s=0}^{\infty} \phi_{t, t+s} q_{i t+s} \\
\text { with } q_{i t+s}=\frac{P_{i t+s} y_{i t+s}-P_{t+s} w_{t+s} n_{i t+s}-P_{t+s} r_{t+s} k_{i t+s-1}-P_{t+s} z_{t+s} h_{i t+s}}{P_{t+s}},
\end{aligned}
$$

where the firm applies the owners' stochastic discount factor $\phi_{t, t+s}=\beta^{s} \frac{\Omega_{t+s} c_{t+s}^{-\sigma}}{\Omega_{t} c_{t}^{-\sigma}}$, subject to $y_{i t+s}=a_{t+s} n_{i t+s}^{v} k_{i t+s-1}^{1-v}, y_{i t+s}=\left(\frac{P_{i t+s}}{P_{t+s}}\right)^{-\varepsilon} y_{t+s}$, and $h_{i t+s}=n_{i t+s}-(1-d) n_{i t+s-1}$, taking the general price level, the real wage and capital rental rate, and firm-level costs per hire $z_{t+s}$ as well as previous period employment and capital $n_{i,-1}$ and $k_{i,-1}$ as given.

Letting $\Psi_{i t}$ be the multiplier on the demand constraint, and $\Theta_{i t}$ the one on (4), the first order conditions read

$$
\begin{aligned}
\Theta_{i t} & =\left(\frac{P_{i t}}{P_{t}}-\Psi_{i t}\right) v a_{t} n_{i t}^{v-1} k_{i t-1}^{1-v}-w_{t}+(1-d) E_{t} \beta \frac{\Omega_{t+1} c_{t+1}^{-\sigma}}{\Omega_{t} c_{t}^{-\sigma}} \Theta_{t+1} \\
\Theta_{i t} & =z_{t} \\
r_{t} & =\left[\frac{P_{i t}}{P_{t}}-\Psi_{i t}\right](1-v) a_{t} n_{i t}^{v} k_{i t-1}^{-v}, \\
0 & =a_{t} n_{i t}^{v} k_{i t-1}^{1-v}\left(\frac{1}{P_{t}}-\varepsilon \Psi_{i t} \frac{1}{P_{i t}}\right) .
\end{aligned}
$$

Note that $\Theta_{i t}$ gives the marginal value of an additional hire to the firm, and is equal to the (per-hire) hiring costs $z_{t}=b x_{t}^{\alpha}$ that are saved when an additional worker is in place; this is the same across firms, and therefore the marginal value of a hire is the same across firms, implying $\Theta_{i t}=\Theta_{t}$. Note that there exists an externality, since an individual firm does not take into account the impact of its own hires $h_{i t}$ on the hiring costs $z_{t}$. 


\subsection{Wage bargaining}

Following Blanchard and Gali (2006) as well as a large part of the macroeconomic literature on unemployment, it is assumed that real wages are determined in a Nash bargain between workers and firms. Let $\omega_{t}^{n}$ be the household's value of being employed, and $\omega_{t}^{u}$ the value of being unemployed at the beginning of $t$. We have

$$
\omega_{t}^{n}=w_{t}-\frac{\chi c_{t}^{\sigma}}{\Omega_{t}}+\beta E_{t} \frac{\Omega_{t+1} c_{t+1}^{-\sigma}}{\Omega_{t} c_{t}^{-\sigma}}\left[d\left(1-x_{t+1}\right) \omega_{t+1}^{u}+\left(1-d\left(1-x_{t+1}\right)\right) \omega_{t+1}^{n}\right] .
$$

Here $d\left(1-x_{t+1}\right)$ is the transition probability from employed to unemployed status $(d$ is the separation rate, and $x_{t+1}$ the job finding rate for period $t+1$, such that $d\left(1-x_{t+1}\right)$ is the probability of being fired and then not finding a job next period). The value of being unemployed is

$$
\omega_{t}^{u}=\beta E_{t} \frac{\Omega_{t+1} c_{t+1}^{-\sigma}}{\Omega_{t} c_{t}^{-\sigma}}\left[\left(1-x_{t+1}\right) \omega_{t+1}^{u}+x_{t+1} \omega_{t+1}^{n}\right] .
$$

The household's surplus in the Nash bargain is thus

$$
\omega_{t}^{n}-\omega_{t}^{u}=w_{t}-\frac{\chi c_{t}^{\sigma}}{\Omega_{t}}+\beta(1-d) E_{t} \frac{\Omega_{t+1} c_{t+1}^{-\sigma}}{\Omega_{t} c_{t}^{-\sigma}}\left[\left(1-x_{t+1}\right)\left(\omega_{t+1}^{n}-\omega_{t+1}^{u}\right)\right] .
$$

The surplus of a firm $i^{\prime}$ s hire $\Theta_{i t}$ is equal to the (per-hire) hiring costs $z_{t}=b x_{t}^{\alpha}$ that are saved when an additional worker is in place. Given that the costs per hire are identical for all firms, $\Theta_{i t}=\Theta_{t}$, firms and households maximize the Nash product

$$
\left(\omega_{t}^{n}-\omega_{t}^{u}\right)^{\kappa}\left(\Theta_{t}\right)^{1-\kappa}, \quad \kappa \in(0,1)
$$

leading to the first order condition

$$
\omega_{t}^{n}-\omega_{t}^{u}=\vartheta b x_{t}^{\alpha}
$$

where $\vartheta=\frac{\kappa}{1-\kappa}$ is the workers' relative bargaining weight. Inserting this into (5) gives the bargained real wage as

$$
w_{t}=\frac{\chi c_{t}^{\sigma}}{\Omega_{t}}+\vartheta b x_{t}^{\alpha}-\beta(1-d) E_{t} \frac{\Omega_{t+1} c_{t+1}^{-\sigma}}{\Omega_{t} c_{t}^{-\sigma}}\left[\left(1-x_{t+1}\right) \vartheta b x_{t+1}^{\alpha}\right] .
$$

\subsection{Government}

Finally, the government levies lump-sum taxes $\tau_{t}$ for purchases of goods $g_{t} \geq 0$ :

$$
g_{t}=\tau_{t} .
$$




\subsection{Rational expectations equilibrium}

We consider a symmetric equilibrium, where firms' choices satisfy $P_{i t}=P_{t}$, as well as $y_{i t}=y_{t}, n_{i t}=n_{t}$ and $k_{i t}=k_{t}$. Hence, their equilibrium behavior can be summarized in terms of aggregate variables only

$$
\begin{aligned}
w_{t} & =\frac{\varepsilon-1}{\varepsilon} v a_{t} n_{t}^{v-1} k_{t-1}^{1-v}-b x_{t}^{\alpha}+b(1-d) E_{t} \beta \frac{\Omega_{t+1} c_{t+1}^{-\sigma}}{\Omega_{t} c_{t}^{-\sigma}} x_{t+1}^{\alpha}, \\
r_{t} & =\frac{\varepsilon-1}{\varepsilon}(1-v) a_{t} n_{t}^{v} k_{t-1}^{-v} \\
q_{t} & =y_{t}-w_{t} n_{t}-r_{t} k_{t-1}-z_{t} h_{t},
\end{aligned}
$$

where $y_{t}=a_{t} n_{t}^{v} k_{t-1}^{1-v}$ and $h_{t}=n_{t}-(1-d) n_{t-1}$.

In a rational expectations equilibrium markets clear, prices adjust in accordance with the plans of households and firms, and, in particular, the bargained real wage will satisfy (6) and the firms' labor demand condition (7). A rational expectations equilibrium then is a set of sequences $\left\{n_{t}, k_{t}, c_{t}, x_{t}, w_{t}, r_{t}\right\}_{t=0}^{\infty}$ satisfying

$$
\begin{aligned}
a_{t} n_{t}^{v} k_{t-1}^{1-v}= & c_{t}+b x_{t}^{\alpha}\left[n_{t}-(1-d) n_{t-1}\right]+g_{t}+k_{t}-(1-\delta) k_{t-1}, \\
\frac{\chi c_{t}^{\sigma}}{\Omega_{t}}= & \frac{\varepsilon-1}{\varepsilon} v a_{t} n_{t}^{v-1} k_{t-1}^{1-v}-(1+\vartheta) b x_{t}^{\alpha} \\
& +\beta b(1-d) E_{t} \frac{\Omega_{t+1} c_{t+1}^{-\sigma}}{\Omega_{t} c_{t}^{-\sigma}}\left(x_{t+1}^{\alpha}+\left(1-x_{t+1}\right) \vartheta x_{t+1}^{\alpha}\right), \\
r_{t}= & \frac{\varepsilon-1}{\varepsilon}(1-v) a_{t} n_{t}^{v} k_{t-1}^{-v}, \\
w_{t}= & \frac{\varepsilon-1}{\varepsilon} v a_{t} n_{t}^{v-1} k_{t-1}^{1-v}-b x_{t}^{\alpha}+\beta E_{t} \frac{\Omega_{t+1} c_{t+1}^{-\sigma}}{\Omega_{t} c_{t}^{-\sigma}} b(1-d) x_{t+1}^{\alpha}, \\
\Omega_{t} c_{t}^{-\sigma}= & \beta E_{t} \Omega_{t+1} c_{t+1}^{-\sigma}\left[r_{t+1}+1-\delta\right], \\
x_{t}= & \frac{n_{t}-(1-d) n_{t-1}}{1-(1-d) n_{t-1}}
\end{aligned}
$$

and the transversality condition $\lim _{t \rightarrow \infty} E_{0} \beta^{t} \Omega_{t} c_{t}^{-\sigma} k_{t}=0$, given a fiscal policy, exogenous sequences $\left\{a_{t}, \Omega_{t}\right\}_{t=0}^{\infty}$, and initial values $k_{-1}>0$ and $n_{-1}>0$.

These equations have straightforward interpretations. (10) is the aggregate resource constraint. (11) is the equilibrium condition for the labor market, derived from combining the bargained real wage (6) with the labor demand condition (13). The firms' optimality condition for capital demand is (12), and (14) is the intertemporal optimality condition for the household sector's consumption/savings decision; finally, (15) is just the definition of labor market tightness. 


\section{Fiscal Policy}

In this section we describe a fiscal policy that maximizes household welfare in the previous model and a reference fiscal policy, which would be optimal in an undistorted economy.

\subsection{Ramsey problem}

We now study the problem of choosing a fiscal policy $\left\{g_{t}\right\}_{t=0}^{\infty}$ that maximizes household welfare (1), which can be rewritten as

$$
E_{0} \sum_{t=0}^{\infty} \beta^{t}\left\{\Omega_{t} \frac{c_{t}^{1-\sigma}}{1-\sigma}+\varphi \frac{g_{t}^{1-\gamma}}{1-\gamma}-\chi n_{t}\right\}
$$

subject to the restrictions imposed by private sector behavior as described in (10) to (15), and the transversality condition. The latter is taken into account for the aggregate intertemporal household budget constraint. Using the period-0 price of one unit of the consumption good in period $t$ for a particular history $s^{t}, Q_{0}\left(s^{t}\right)=Q_{t-1, t}\left(s^{t-1}, s_{t}\right)$ $Q_{t-2, t-1}\left(s^{t-2}, s_{t-1}\right) \ldots Q_{0,1}\left(s^{0}, s_{1}\right)$, a representative household's intertemporal budget constraint can be written as

$$
\begin{aligned}
\widetilde{r_{0}}\left(s_{0}\right) k_{-1}= & \sum_{t=0}^{\infty} \sum_{s^{t}} Q_{0}\left(s^{t}\right)\left(c_{t}\left(s^{t}\right)-w_{t}\left(s^{t}\right) n_{t}\left(s^{t}\right)-q_{t}\left(s^{t}\right)+g_{t}\left(s^{t}\right)\right) \\
& +\lim _{t \rightarrow \infty} \sum_{s^{t}} Q_{0}\left(s^{t}\right) k_{t}\left(s^{t}\right)
\end{aligned}
$$

where we used $g_{t}\left(s^{t}\right)=\tau_{t}\left(s^{t}\right)$ and defined $\widetilde{r_{0}}\left(s_{0}\right)=1+r_{0}\left(s_{0}\right)-\delta$. Applying the household first order condition $\phi_{t, t+1}=\frac{Q_{t, t+1}\left(s^{t}, s_{t+1}\right)}{\pi\left(s^{t+1} \mid s^{t}\right)}=\beta \frac{\Omega_{t+1} c_{t+1}^{-\sigma}\left(s^{t+1}\right)}{\Omega_{t} c_{t}^{-\sigma}\left(s_{0}\right)}$, which implies $Q_{0}\left(s^{t}\right)=$ $\beta^{t} \pi\left(s^{t}\right) \frac{\Omega_{t} c_{t}^{-\sigma}\left(s^{t}\right)}{\Omega_{0} c_{0}^{-\sigma}\left(s_{0}\right)}$, the intertemporal budget constraint can be rewritten as

$$
\begin{aligned}
\widetilde{r_{0}}\left(s_{0}\right) k_{-1}= & \sum_{t=0}^{\infty} \sum_{s^{t}} \pi\left(s^{t}\right) \beta^{t} \frac{\Omega_{t} c_{t}^{-\sigma}\left(s^{t}\right)}{\Omega_{0} c_{0}^{-\sigma}\left(s_{0}\right)}\left(c_{t}\left(s^{t}\right)-w_{t}\left(s^{t}\right) n_{t}\left(s^{t}\right)-q_{t}\left(s^{t}\right)+g_{t}\left(s^{t}\right)\right) \\
& +\lim _{t \rightarrow \infty} \beta^{t} \sum_{s^{t}} \pi\left(s^{t}\right) \frac{\Omega_{t} c_{t}^{-\sigma}\left(s^{t}\right)}{\Omega_{0} c_{0}^{-\sigma}\left(s_{0}\right)} k_{t}\left(s^{t}\right) .
\end{aligned}
$$

Further, using the transversality condition and omitting the reference to the state for notational simplicity gives

$$
\widetilde{r_{0}} k_{-1} \Omega_{0} c_{0}^{-\sigma}=E_{0} \sum_{t=0}^{\infty} \beta^{t} \Omega_{t} c_{t}^{-\sigma}\left(c_{t}-w_{t} n_{t}-q_{t}+g_{t}\right),
$$


Using the definition of profits $q_{t}(9)$ and the resource constraint (10) leads to

$$
\widetilde{r_{0}} k_{-1} \Omega_{0} c_{0}^{-\sigma}=E_{0} \sum_{t=0}^{\infty} \beta^{t} \Omega_{t} c_{t}^{-\sigma}\left((1-\delta) k_{t-1}-k_{t}+\frac{\varepsilon-1}{\varepsilon}(1-v) a_{t} n_{t}^{v} k_{t-1}^{1-v}\right)
$$

where $r_{t}$ has been eliminated by the private sector equilibrium condition (12).

An optimal Ramsey policy is a sequence $\left\{g_{t}\right\}_{t=0}^{\infty}$ that implements a rational expectations equilibrium that yields the highest level of household welfare. Thus, it maximizes (16) subject to (10) to (15) and (18), given $k_{-1}$ and $n_{-1}$. Throughout the analysis, we assume that the policy maker can credibly commit himself, but we ignore the initial period $(t=0)$, and restrict our attention to Markov perfect equilibria. The rational expectations equilibrium under an optimal Ramsey problem is characterized in appendix 8.1. In deriving the Ramsey policy, we ignore the well known problem that the policy maker's decision rules will be different for the first period in which the policy is implemented. This is justified by the fact that we are only interested in making statements about the deterministic steady state as well as about business cycle fluctuations around it, while we do not analyze the transition path from the initial values towards the steady state. For the numerical analysis, we further assume that the initial values for the predetermined variables are equal to their values in the deterministic steady state.

\subsection{Reference policy}

Below we will compare the Ramsey policy with a benchmark policy. The benchmark that we will refer to is derived from the first best allocation that a social planner would choose in a frictionless version of the economy that is only subject to technology shocks, i.e. in a basic RBC model with useful government expenditures. In that scenario, a social planner would implement the first best allocation by maximizing the criterion function

$$
E_{0} \sum_{t=0}^{\infty} \beta^{t}\left\{\frac{c_{t}^{1-\sigma}}{1-\sigma}+\varphi \frac{g_{t}^{1-\gamma}}{1-\gamma}-\chi n_{t}\right\}
$$

subject to the technological constraint

$$
a_{t} n_{t}^{v} k_{t-1}^{1-v}=c_{t}+g_{t}+k_{t}-(1-\delta) k_{t-1}
$$

which is equal to the economy's aggregate resource constraint (10) under the restriction that there are no hiring costs and thus no labor market frictions. The first order conditions of this problem are the familiar conditions for optimal allocation in the frictionless real business cycle model, among which is

$$
c_{t}^{-\sigma}=\varphi g_{t}^{-\gamma}
$$


This condition requires that the marginal rate of substitution between public and private consumption $\left(c_{t}^{-\sigma} / \varphi g_{t}^{-\gamma}\right)$ be equal to the marginal rate of transformation (the latter being equal to one). Below, we will choose $\sigma=\gamma=1$ as baseline parameter values. In that case, the preceding condition boils down to a constant ratio of government spending to consumption,

$$
g_{t} / c_{t}=\varphi
$$

We use (21) as a reference policy by considering it as a simple benchmark rule that a non-optimizing policy maker might choose. This simple rule just requires the policy maker to adjust government spending in lockstep with private consumption. Note that this would actually coincide with the optimal Ramsey policy if there were $i$ ) no labor frictions, ii) perfect competition on goods markets, and iii) only technological shocks. To be precise, the corresponding reference allocation to which we compare the Ramsey allocation consists of (21) as a simple rule for the determination of fiscal policy, and (10) to (15) as a description of the private sector.

\section{Results}

In what follows, we present results from numerical experiments with the optimal policy described above, and given in more detail in appendix 8.1. We first solve the steady state of the Ramsey allocation (given in appendix 8.2) numerically as a set of static nonlinear equations, given parameters, and then perform local approximations to the dynamic equilibrium conditions to generate impulse responses to technology and demand shocks under the Ramsey policy, and under the reference policy $g_{t} / c_{t}=\varphi$.

\subsection{Parameterization}

We need to determine the 21 parameters and steady state values $\{\sigma, \gamma, \delta, \beta, v, \varepsilon, \alpha$, $\vartheta, n, d, c, g, k, w, \varphi, \chi, b\}$ and $\{\Gamma, \lambda, \psi, \mu\}$, where the latter four variables are the Lagrangian multipliers of the Ramsey policy problem described in detail in appendix 8.1. The steady state consists of the 9 relations in (28) - (36) in appendix 8.2. Hence, we need 12 restrictions in order to let the steady state equations determine the remaining 9 steady state quantities.

The first 6 restrictions come from setting the parameters $\sigma, \gamma, \delta, \beta, v, \varepsilon$ to standard values often used in the literature. In particular, we assume utility to be logarithmic, i.e. $\sigma=1, \gamma=1$, and the discount factor to be compatible with a yearly three per cent real interest rate, which amounts to setting $\beta=0.9926$ for a quarterly interpretation of the model. The labor share in production is set at $v=0.7$, and the depreciation rate is set at $\delta=0.025 .^{5}$ The value of the firms' demand elasticity is set to $\varepsilon=6$ to imply a markup of

\footnotetext{
${ }^{5}$ Using the European Commission's annual macroeconomic data base (see
} 
price over marginal cost of 1.2 , which is what empirical studies suggest to be reasonable (e.g. Basu and Fernald, 1997).

Then, we impose 5 restrictions related to the labor market part. First, we are looking for parameters to be compatible with a 10 per cent unemployment rate in the steady state (the economy we have in mind is thus more of the continental European than the U.S. type). This amounts to choosing the utility parameter $\chi$ such that $n=0.9$ results in the steady state. Then, we follow Blanchard and Gali (2006) in setting the curvature of the hiring cost function to $\alpha=1$. We further assume that labor's weight in the bargaining process is twice as large as the one of firms, $\vartheta=2$, which implies that the Hosios condition is not satsified. We further use $d=0.1$ as in one of their computational examples. Finally, we also follow Blanchard and Gali (2006) to adjust the parameter $b$ such that in the calibrated steady state the costs of hiring, $b x^{\alpha} d n$, are a certain percentage $\Delta \equiv b x^{\alpha} d n /\left(n^{v} k^{1-v}\right)$ of steady state output, which leads to a calibrated value for the constant $b$; in practice, we specify $\Delta$ to be 0.005 such that hiring costs represent one half per cent of output.

The remaining restriction comes from specifying the size of government in relation to the private sector; this is in keeping with the RBC tradition of calibrating a model to be compatible with certain great ratios. Here, we require the ratio of government spending to private consumption to equal $g / c=0.3729$ under the Ramsey policy, since this is the empirical average of dividing real total final government consumption by real private consumption expenditures in France, Germany, and Italy, where the average is taken over the three countries for the time period 1970-2006 (source: European Commission, AMECO database, annual data). The utility parameter $\varphi$ is then chosen to produce this $g / c$ ratio in the steady state, which leads to $\varphi=0.3116$. The following table 1 gives an overview over the chosen or calibrated parameter values.

Table 1 Parameter values

\begin{tabular}{|c|c|c|c|c|c|c|c|c|c|c|c|c|}
\hline & $\beta$ & $\delta$ & $\sigma$ & $\gamma$ & $v$ & $\varepsilon$ & $\alpha$ & $\vartheta$ & $\chi$ & $\varphi$ & $d$ & $b$ \\
\hline & 0.9926 & 0.025 & 1 & 1 & 0.7 & 6 & 1 & 2 & 0.9981 & 0.3116 & 0.1 & 0.2532 \\
\hline
\end{tabular}

\subsection{Steady state results}

The following table 2 shows values of the endogenous variables in the deterministic steady state (with the exogenous driving processes being at their steady state values $a=1$ and $\Omega=1$ ), in both cases obtained by applying the parameter set given in table 1 , for two policy specifications: the Ramsey optimal policy described in section 3.1 (with the resulting equilibrium conditions listed in appendix 8.1), and the reference policy described be 0.69 for the U.S. and 0.71 for the Euro area. 
in section 3.2, which simply amounts to setting the ratio of government spending to private consumption to the exogenously given constant $\varphi$.

Table 2 Steady state values

\begin{tabular}{|l|c|c|c|c|c|c|c|c|}
\hline & $n$ & $c$ & $g$ & $k$ & $w$ & $g / c$ & $g / y$ & $c / y$ \\
\hline Ramsey & 0.9000 & 1.2618 & 0.4705 & 16.6301 & 1.3865 & 0.3729 & 0.2180 & 0.5845 \\
\hline$g / c=$ exog. & 0.8776 & 1.2889 & 0.4016 & 16.2173 & 1.3880 & 0.3116 & 0.1908 & 0.6123 \\
\hline
\end{tabular}

In comparing both policy results, first note that the reference policy exogenously specifies $g / c=\varphi=0.3116$, the level to which we have calibrated the utility parameter $\varphi$. The Ramsey optimal policy, in contrast, for the same set of parameters (and thus for the same value of $\varphi$, of course) results in a higher ratio of $g / c=0.3729>\varphi$. Furthermore, not only is the ratio of government spending to private consumption higher under the optimal Ramsey policy, but it is also true that the level of government spending is higher, while the level of private consumption is lower. Moreover, under the Ramsey policy the capital stock is slightly higher (the capital output ratio is actually the same, since output is also higher in the Ramsey model), such that the real wage is very slightly lower. Most notably, employment is higher under the Ramsey optimal policy.

The explanation of these differences in steady state values of the optimal Ramsey policy versus the suboptimal reference policy is as follows. For any given level of government spending, employment is inefficiently low due to the labor market friction. On the one hand, the Ramsey planner has an incentive to equalize marginal utilities of consumption and spending, which under the maintained parameterization would amount to setting $g / c=\varphi$, but on the other hand wants to correct for the labor market externality. He thus chooses to raise the government spending share above the level suggested by the reference policy. This reduces consumption and the consumption output ratio, since the government reduces the resources available to the private sector. On the other hand, the higher $g / c$ ratio under the Ramsey policy raises employment. Employment can rise because the decrease in consumption induced by higher government spending tends to lower the reservation wage (the marginal rate of substitution between consumption and leisure) in the wage bargaining process and to raise employment. This brings employment closer to the efficient level, such that the Ramsey planner considers the implied consumption sacrifice worthwhile. From the complementarity of capital and labor in production, this also raises the capital stock, which in turn mitigates the wage differential between the two policies to a point where the real wage rates are almost equal.

To put his in perspective, recall that the reference policy has been specified as the policy that would be first best optimal in the absence of labor market frictions. Thus, the deviation of the Ramsey optimal policy from the reference policy can be seen as the policy change that is mandated by the fact that there are, in fact, frictions that raise unemployment in this economy. Taking account of labor frictions, thus, the Ramsey 
optimal planner pushes up employment relatively to the reference case by choosing higher government spending than what a simple calculation based just on comparing marginal utilities of public and private spending would suggest. This produces higher output in steady state, although it comes at the cost of lower private consumption (both as a level and in relation to output).

\subsection{Welfare comparison}

We can also quantify the welfare difference between the Ramsey policy and the reference policy in a deterministic steady state. To do so, we calculate the per cent loss of steady state consumption that is equivalent to the relative utility loss that households would suffer by a permanent switch from the Ramsey to the alternative policy. The details of the computation are given in appendix 8.3. For the parameterization chosen here, the welfare loss of the reference policy relative to the Ramsey policy amounts to 0.57 per cent of steady state consumption. Thus, agents would be willing to permanently sacrifice more than half a percentage point of consumption in order to be able to benefit from the optimal Ramsey policy.

\subsection{Fiscal stabilization}

We now turn to the stabilization aspect of the optimal fiscal policy. To study the cyclical properties under the Ramsey policy, we take a loglinear approximation of the equilibrium conditions at the deterministic steady state. ${ }^{6}$ We found the local equilibrium system to be saddle path stable in each case. Figure 1 shows percentage impulse responses to a positive one percent autocorrelated $(\rho=0.9)$ technology shock. In figure 1 , the responses under the optimal Ramsey policy are shown by solid (blue) lines, whereas those under the reference policy are shown as dashed (red) lines.

Obviously, the levels of all variables increase under both policies, whereas the ratio of government spending to consumption (shown in the lower left panel) declines under the Ramsey policy. Thus, government spending is adjusted procyclically by the Ramsey planner, while its ratio to private consumption moves countercyclically.

That the levels of all variables rise is no surprise, since resources expand through the positive productivity shock. Fiscal policy should thus let consumption and government spending expand, too. However, under the Ramsey policy government spending increases markedly less than under the reference policy. The reason for the optimality of the less procyclical response is that the shock induced increase in the marginal product of labor also raises the demand for labor, such that employment increases. But temporary employment changes imply resource losses due to hiring costs, which the Ramsey planner seeks to reduce. Under the Ramsey policy employment adjustments are less pronounced,

\footnotetext{
${ }^{6}$ Computations are carried out in Dynare (see www.cepremap.cnrs.fr/dynare).
} 

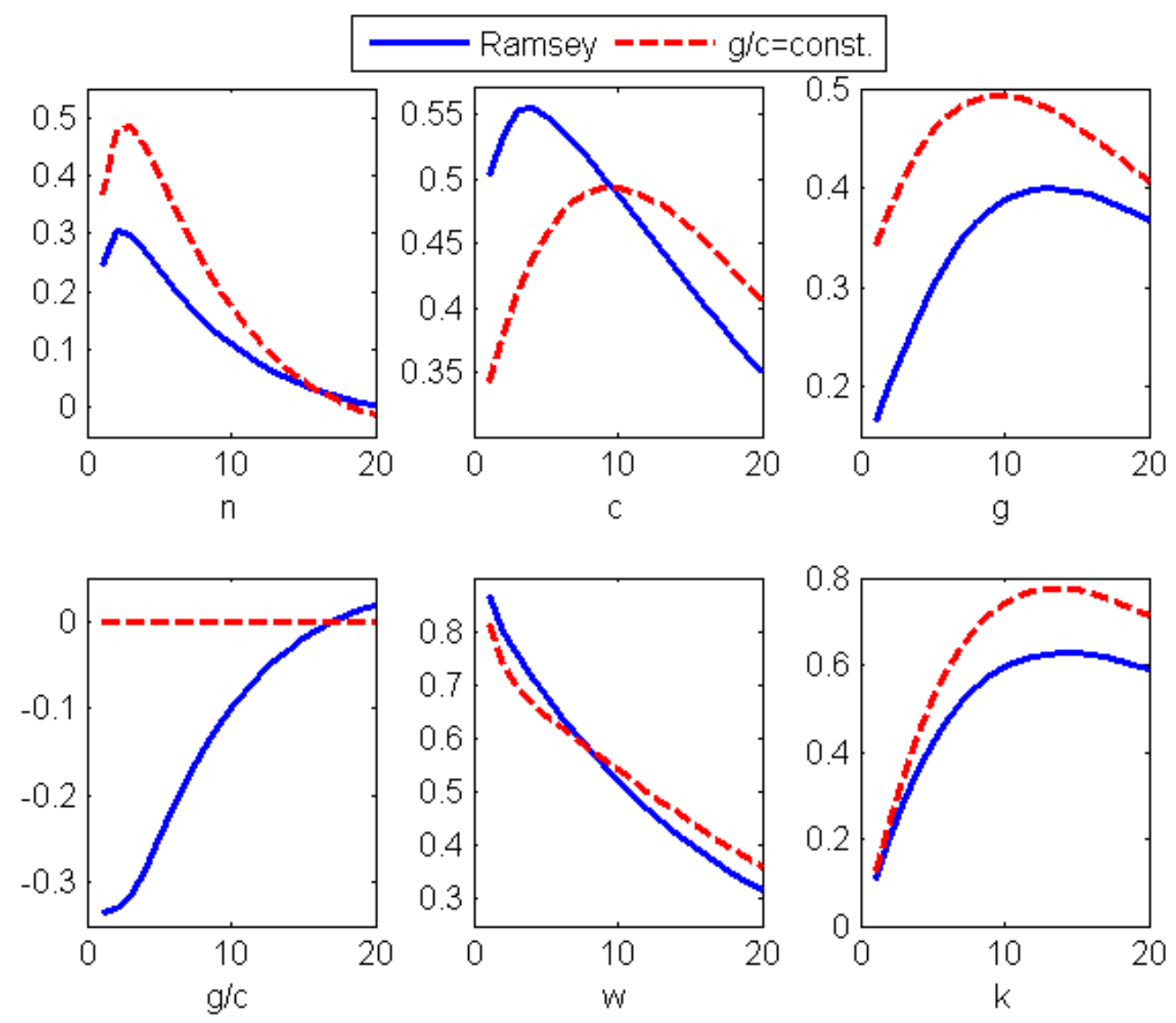

Figure 1: Impulse responses to technology shock.

as evidenced in the upper left panel, than under the reference policy, which ignores the hiring costs since it does not recognize the fact that the labor market is friction ridden. In this sense, the optimal policy partly stabilizes employment by dampening its procyclical response to a technology shock.

Smaller employment adjustments are brought about through the limited increase in government spending. By choosing to let $g_{t}$ expand only slightly after the technology shock, the Ramsey planner leaves room for private consumption to expand markedly more than under the reference policy. This increases the wage aspirations of workers, since it tends to raise the marginal rate of substitution between consumption and leisure. As a partial effect, this would imply a wage increase (relative to the comparison policy) and thus a dampened employment increase. However, in equilibrium labor demand is also changed, and is also influenced by capital accumulation. But under the Ramsey policy, since private consumption increases more strongly, saving and thus investment is lower, and thus the capital stock expands less. There is therefore lower labor demand than under the comparison policy, and hence, as a net effect, the real wage response is practically identical in equilibrium under both policies.

Things are somewhat different under demand shocks. Figure 2 shows the percentage 
impulse responses to a one percent shock to $\Omega_{t}$ (with $\rho=0.9$ ) for the same set of parameters that were underlying figure 1 .
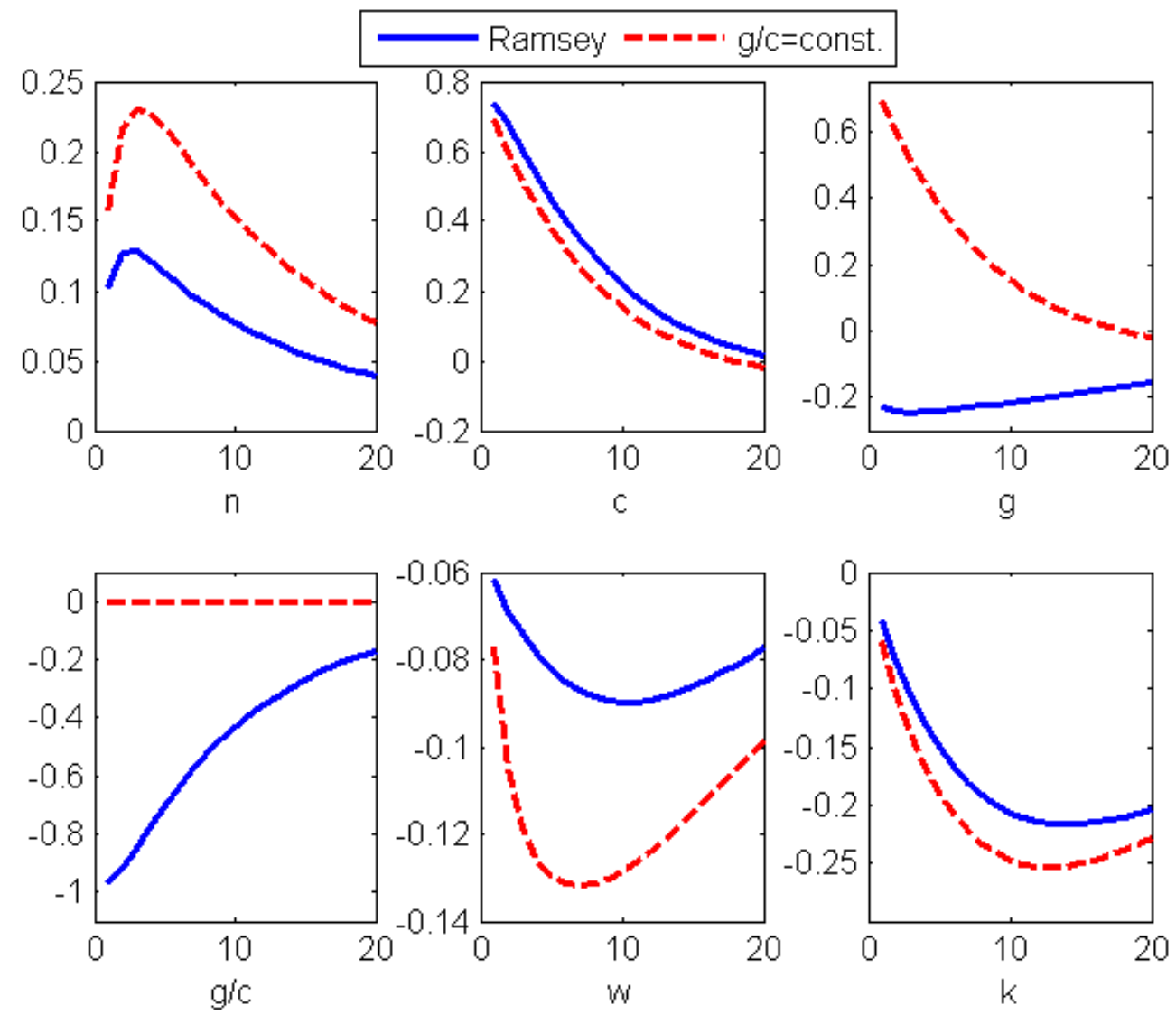

Figure 2: Impulse responses to demand shock.

Here, employment and consumption increase in both specifications, whereas the capital stock decreases. The level of government spending increases, consequently, under the reference policy, but declines under the Ramsey policy. Thus, optimal fiscal policy is countercyclical both in relation to consumption as well as in levels under demand shocks.

The reason is, in the first place, that the shock directly raises the marginal utility of consumption by construction. Thus, one incentive the Ramsey policy maker faces is to keep the marginal utility of public spending in line with the one of private consumption, and thus to decrease government spending while consumption increases. Thus, the ratio $g_{t} / c_{t}$ decreases strongly under the optimal policy both from the countercyclical response of $g_{t}$ as well as from the procyclical response of $c_{t}$.

Importantly, the Ramsey policy implies a less volatile positive employment response, while private consumption reacts marginally more than under the reference policy. This shows the second incentive that the Ramsey planner faces, namely to economize on the resource costs entailed by temporary labor input adjustments. By lowering government spending during the demand led boom, the planner increases the resources available for 
private consumption, hence the latter increases more than under the reference policy. This means that saving has to decline less, in comparison, and consequently the drop in investment and thus in the capital stock is attenuated. Therefore, the real wage decline is mitigated, which again helps to limit the employment increase. In the end, the Ramsey planner tends to stabilize employment at the costs of a slightly higher consumption responses, and a markedly smaller adjustment of government spending.

To further illustrate the dynamic properties of the model, the following table 3 shows the relative volatilities of employment, consumption, and government spending. Each table entry shows the ratio of the unconditional standard deviations of the respective variable under the Ramsey policy relatively to the reference policy. This is shown separately for each shock.

Table 3 Relative volatilities

$\begin{array}{lccc} & n_{t} & c_{t} & g_{t} \\ \text { technology shocks } & 0.63 & 0.97 & 1.01 \\ \text { demand shocks } & 0.54 & 1.11 & 0.94\end{array}$

Under technology shocks, both employment and consumption are less volatile with the Ramsey policy in comparison to the reference policy. The difference is pronounced for employment, and very weak for consumption. Government spending is very slightly more volatile. Thus, even though the optimal policy implies an initially stronger consumption response to stabilize the employment response, this is also accompanied by a faster return to the steady state, such that the unconditional standard deviation is actually lower. This is different in the case of demand shocks, where the strong gain in relative employment stabilization under the optimal policy is associated with an increased volatility of consumption, while government spending is slightly less volatile in the Ramsey case under demand shocks.

To sum up, the Ramsey planner aims at stabilizing (un-) employment over the business cycle. Under technology shocks, this is implemented by a procyclical response of the level of government spending $g_{t}$ that entails a countercyclical variation in the $g_{t} / c_{t}$ ratio. In the case of demand shocks, government spending is countercyclical both in levels and in the ratio sense. Under demand shocks, the optimal policy buys stabilization of employment at the costs of a consumption pattern that is more volatile under the Ramsey policy than under the reference policy. The Ramsey planner thus trades off the resource costs of employment variation against the costs of deviating from equalizing the marginal rate of substitution and the marginal rate of transformation between $g_{t}$ and $c_{t}$. 


\section{$5 \quad$ Sticky prices}

The conventional view is that stabilization policy should be conducted by monetary, rather than by fiscal policy (e.g. Taylor, 2000). Monetary policy can arguably react more smoothly and with less bureaucratic effort to current developments and is thus in a better position to fulfill the task of stabilizing the economy under the influence of shocks. Therefore, previous studies of fiscal stabilization policy have concentrated on cases where monetary policy is incapable of fulfilling the stabilization task for some special reason, e.g. in a monetary union where monetary policy can only react to union wide developments and must leave coping with idiosyncratic regional shocks to fiscal policy (see Beetsma and Jensen, 2005, Gali and Monacelli, 2007).

Our approach is different in that we argue that there is a role for fiscal stabilization policy even in a situation where monetary policy is fully capable of fulfilling its job. Moreover, the optimal fiscal behavior is not qualitatively different from what we described in the previous sections where we abstracted from monetary policy. The reason for this result is as follows: in order for monetary stabilization to have a meaningful role, we introduce a nominal friction; in particular, in keeping with the large New Keynesian literature, we focus on price stickiness. But in a model with unemployment, this adds a second friction (price setting) to the already existing labor market friction. Since optimal monetary policy alone is not able to cope with both distortions, there remains a role for fiscal stabilization policy. Intuitively, monetary policy takes responsibility for eliminating the distortion from pricing frictions, and thus strives to stabilize the price level. The remaining distortion, the labor market friction, is taken care of by fiscal policy; the way this is implemented is very similar to what has been derived for the flexible price economy above.

To demonstrate this, we introduce price stickiness in this section. Firms face quadratic price adjustment costs, as in Rotemberg (1982). Monetary policy is carried out by choosing the nominal interest rate on short-term government bonds. The policy that we consider is jointly optimal (Ramsey) fiscal and monetary policy. Following a large New Keynesian literature, we do not model money demand in order to avoid the complications from transactions frictions; thus, the model we employ is of the 'cashless' variety (Woodford, 2003). As a consequence, the optimal steady state inflation rate will be zero.

We assume that one of the assets that households have access to is a one period riskless nominal bond $B_{t}$, which earns a nominal rate of return of $R_{t}-1$ from period $t$ to period $t+1$, and is initial endowed with $B_{-1}=0$. Letting $P_{t}$ the price level of the final good, and $\pi_{t} \equiv P_{t} / P_{t-1}$ the inflation rate, household behavior is thus complemented by an additional Euler equation reading

$$
\Omega_{t} c_{t}^{-\sigma}=\beta E_{t} \Omega_{t+1} c_{t+1}^{-\sigma} \frac{R_{t}}{\pi_{t+1}} .
$$

To change a price, an intermediate good producing firm $i$ has to incur real adjustment 
costs $c a_{i t}$, assumed to be given by

$$
c a_{i t}=\frac{\kappa}{2}\left(\frac{P_{i t}}{P_{i t-1}}-1\right)^{2}
$$

where $\kappa>0$ is a constant. Firms are assumed to maximize the expected discounted stream of current and future profits.

The firm's first order conditions are derived in appendix 8.4. When firms are symmetric, each firm sets the same price and employs the same amount of input factors. The first order conditions can be summarized as factor demand conditions depending on current and expected inflation,

$$
\begin{aligned}
w_{t}= & \frac{\varepsilon-1}{\varepsilon} v a_{t} n_{t}^{v-1} k_{t-1}^{1-v}-b x_{t}^{\alpha}+\beta E_{t} \frac{\Omega_{t+1} c_{t+1}^{-\sigma}}{\Omega_{t} c_{t}^{-\sigma}} b(1-d) x_{t+1}^{\alpha}+\frac{1}{n_{t}} \frac{v}{\varepsilon} \kappa\left(\pi_{t}-1\right) \pi_{t} \\
& -\frac{1}{n_{t}} \frac{v}{\varepsilon} \beta E_{t} \frac{\Omega_{t+1} c_{t+1}^{-\sigma}}{\Omega_{t} c_{t}^{-\sigma}} \kappa\left(\pi_{t+1}-1\right) \pi_{t+1} \\
r_{t}= & \left.\frac{\varepsilon-1}{\varepsilon}(1-v) a_{t} n_{t}^{v} k_{t-1}^{-v}+\frac{1-v}{\varepsilon k_{t-1}} \kappa\left(\pi_{t}-1\right) \pi_{t}-\frac{1-v}{\varepsilon k_{t-1}} \beta E_{t} \frac{\Omega_{t+1} c_{t+1}^{-\sigma}}{\Omega_{t} c_{t}^{-\sigma}} \kappa\left(\pi_{t+1}-1\right) \pi_{(+25)}\right)
\end{aligned}
$$

Symmetric period profits $q_{t}$ of each firm are given by

$$
q_{t}=y_{t}-w_{t} n_{t}-r_{t} k_{t-1}-z_{t} h_{t}-\frac{\kappa}{2}\left(\pi_{t}-1\right)^{2} .
$$

The wage bargaining problem is unaltered, and the bargained wage again satisfies (6).

In symmetric equilibrium, markets clear, and the resource constraint now reads

$$
a_{t} n_{t}^{v} k_{t-1}^{1-v}=c_{t}+b x_{t}^{\alpha}\left[n_{t}-(1-d) n_{t-1}\right]+g_{t}+k_{t}-(1-\delta) k_{t-1}+\frac{\kappa}{2}\left(\pi_{t}-1\right)^{2},
$$

which is different from the above flexible price case only because of the appearance of the last term which is the resource cost of price adjustments.

The Ramsey planner maximizes household welfare (16) subject to (17), (27), (15), (6), and (23). Also, the bond Euler equation (22) is part of the constraints; however, we will assume that monetary policy is conducted as nominal interest rate setting, such that $R_{t}$ is a policy instrument. Under this assumption, (22) need not be used as a constraint. The first order conditions for this problem are given in appendix 8.4.

Figure 3 gives the impulse responses to a one percent autocorrelated technology shock; the model is parameterized as in the flexible price case discussed above, and in addition the parameter of the price adjustment cost function has been chosen to be $\kappa=20$ (while this choice is somewhat arbitrary in this context, we ascertained that the degree of price stickiness does not qualitatively affect the conclusions with optimal monetary policy). Figure 4 shows the same for an autocorrelated demand shock.

As can be seen from figures 3 and 4 , the qualitative properties of the responses of 

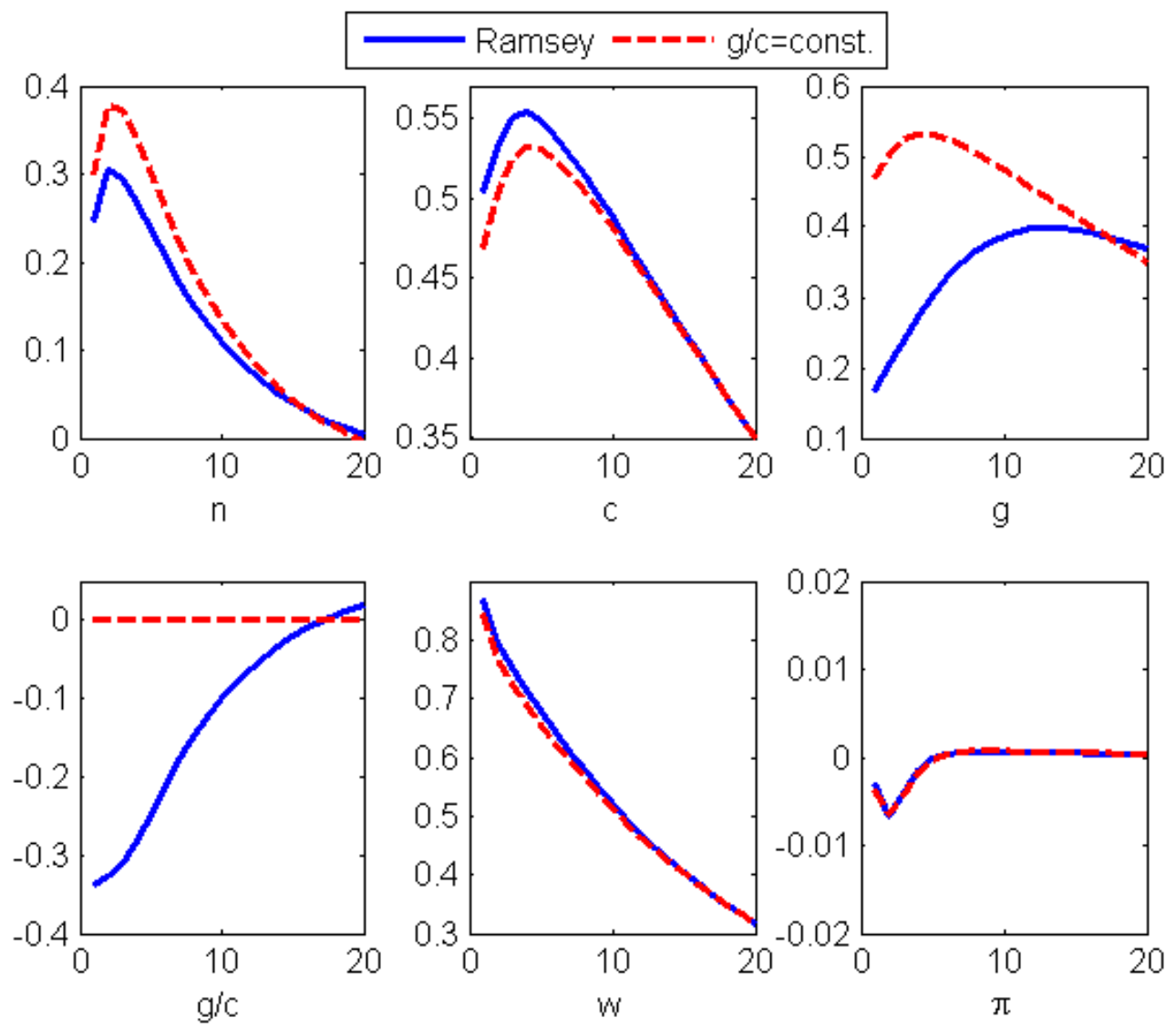

Figure 3: Impulse responses to technology shock.

employment, consumption, government spending are the same as in the flexible price case. The inflation rate, shown in the lower right panel in the figures, reacts only very weakly, an order of magnitude less than the other variables. Thus, the optimal policy is to keep the price level almost constant, while allowing the real variables to adjust much in the same way as under flexible prices. The only difference that adding price stickiness and optimal interest rate setting appears to make lies in quantitative changes of the strength of the responses.

Thus, there is a rather clear cut interpretation: in the presence of price stickiness and labor market frictions, the jointly optimal fiscal and monetary policy aims at replicating, approximately at least, the flexible price outcome by keeping the price level close to being constant. This result is well known from the New Keynesian literature, of course. What is new here is the point that there remains a separate role for fiscal policy, which consists of optimizing the trade-off between public goods provision and employment stabilization. This role for fiscal policy is the same, qualitatively, as under flexible prices. Consequently, this result may be seen as prescribing a simple 'policy assignment': while monetary policy optimally takes care of nominal frictions, and thus predominantly stabilizes the price level, fiscal policy takes care of the real frictions, which in our case means that it aims at 


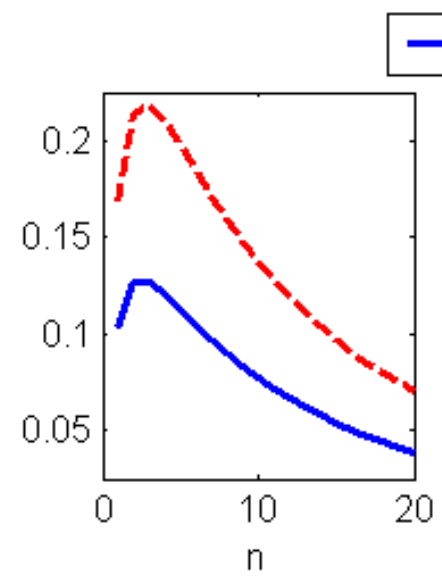

Ramsey ーーーー・ $g / c=$ const.
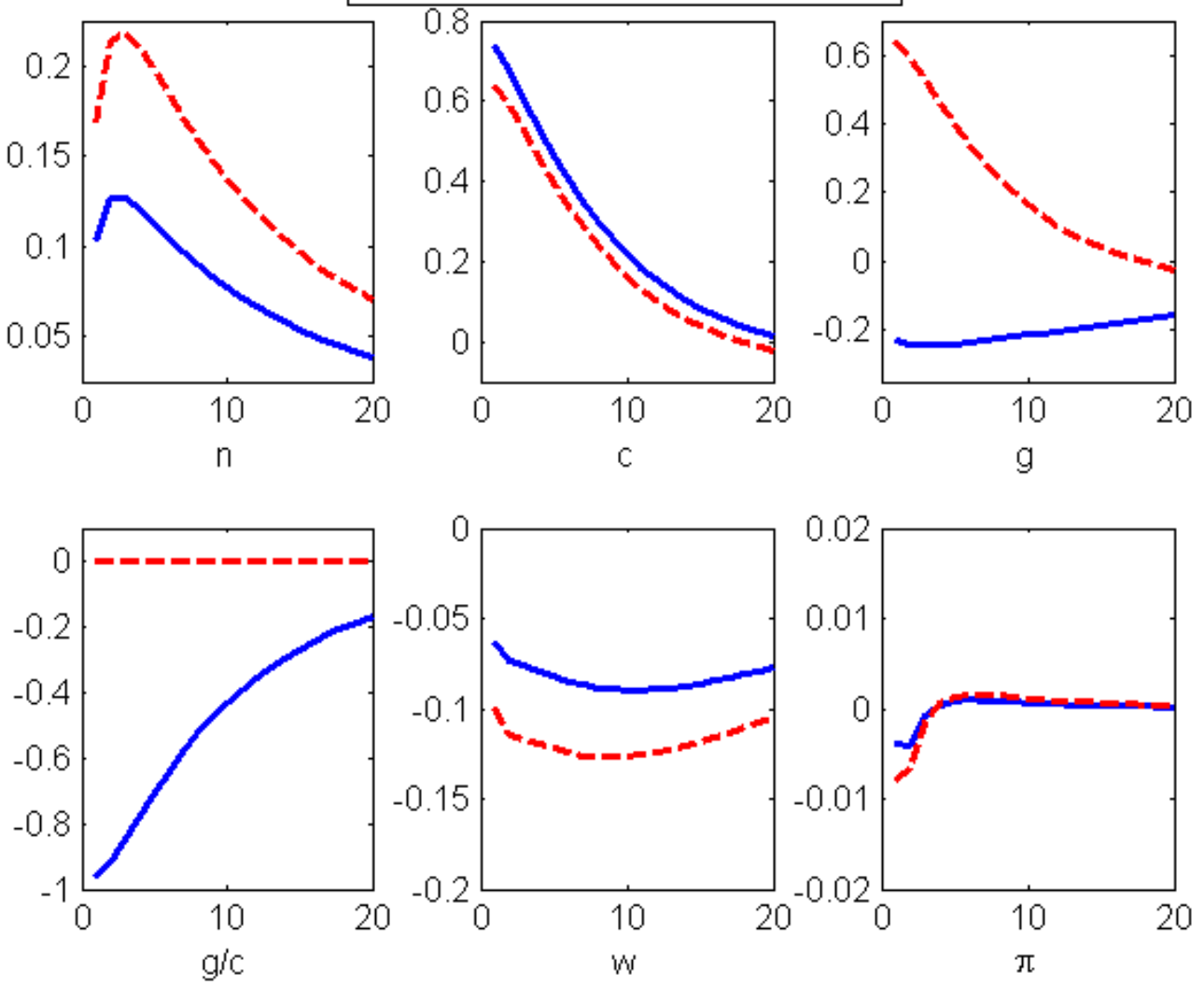

Figure 4: Impulse responses to demand shock.

stabilizing employment.

\section{Conclusion}

In this paper, we have analyzed the optimal conduct of government spending policy in a model with frictional unemployment. The central result is that the optimal provision of public goods ceases to be the only concern of a benvolent Ramsey policy maker. Instead, the fact that employment reallocations are costly in a world with labor market frictions leads to departures from the policy of equating marginal rates of substitution and transformation between public and private consumption that would be optimal in a frictionless world. In particular, the optimal fiscal policy uses government spending to partially stabilize employment. In the case of supply shocks, this is implemented through a moderately procyclical spending policy, while in the case of private demand shocks, it leads to a countercyclical spending policy. We also show that nominal price stickiness does not change this conclusion if monetary and fiscal policy are chosen to be jointly optimal.

There are a number of possible extensions that could also fruitfully be analyzed. One point is that so far we have only considered lump-sum tax finance in order to concentrate 
on the spending side of the budget; however, it should be interesting to integrate our arguments with optimal taxation approaches under distortionary income taxes. Another aspect that might deserve a closer look is the role of fiscal policy in settings where the monetary policy problem is more complicated. For example, Blanchard and Gali (2006) report that under the assumption of an exogenous real wage rigidity there is a trade-off for monetary policy in so far as stabilizing the price level is no longer optimal under technology shocks. It might be interesting to analyze in how far fiscal policy could be helpful in resolving such a trade-off. Finally, it would be worthwhile to explore the role of fiscal policies under different specifications for wage setting and labor market institutions. We intend to address these extensions in future research. 


\section{$7 \quad$ References}

Arsenau, D.M. and S.K. Chugh, 2007, Ramsey Meets Hosios: The Optimal Capital Tax and Labor Market Effciency, International Finance Discussion Paper no. 870. , Board of Governors of the Federal Reserve System.

Basu, S. and J.G. Fernald, 1997, Returns to Scale in U.S. Production: Estimates and Implications, Journal of Political Economy, 105, 249-83.

Baxter, M. and R.G. King, 1993, Fiscal Policy in General Equilibrium, American Economic Review 83, 315-334.

Beetsma, R. and H. Jensen, 2005, Monetary and fiscal policy interactions in a microfounded model of a monetary union, Journal of International Economics, 67, 320-352.

Benigno, P. and Woodford, M., 2003, Optimal monetary and fiscal policy: a linear quadratic approach, in: NBER Macroeconomics Annual, MIT Press, 2003.

Blanchard, O. and J. Gali, 2006, A New Keynesian Model with Unemployment, MIT.

Chari, V. V., L.J. Christiano, and P.J. Kehoe, 1994, Optimal Fiscal Policy in a Business Cycle Model, Journal of Political Economy, 102, 617-652.

Clarida, R., J. Galí, and M. Gertler, 1999, The Science of Monetary Policy: A New Keynesian Perspective, Journal of Economic Literature 37, 1661-1707.

Domeij, D., 2005, Optimal Capital Taxation and Labor Market Search, Review of Economic Dynamics, 8, 623-650.

Faia, E., 2007, Optimal Monetary Policy Rules with Labor Market Frictions, Journal Economic Dynamics and Control, Forthcoming.

Gali, J. and T. Monacelli, 2005, Optimal Monetary and Fiscal Policy in a Currency Union, NBER Working Papers 11815, National Bureau of Economic Research.

Gertler, M. and A. Trigari, 2006, Unemployment Fluctuations with Staggered Nash Wage Bargaining, New York University.

Krause, M.U. and T.A. Lubik, 2007, The (Ir)relevance of Real Wage Rigidity in the New Keynesian Model with Search Frictions, Journal of Monetary Economics, 55, 706-727.

Lansing, K., 1997, Optimal Fiscal Policy in a Business Cycle Model with Public Capital, The Canadian Journal of Economics, 31, 337-364.

Merz, M., 1995, Search in the Labor Market and the Real Business Cycle, Journal of Monetary Economics 36, 269-300.

Mortensen, D. and C. Pissarides, 1994, Job Creation and Job Destruction in the Theory of Unemployment, Review of Economic Studies 61, 397-415.

Rotemberg, J., 1982, Monopolistic Price Adjustment and Aggregate Output, Review of Economic Studies, 49, 517-531.

Schmitt-Grohe, S. and M. Uribe, 2004, Optimal Fiscal and Monetary Policy under Sticky Prices, Journal of Economic Theory, 114, 198-230. 
Taylor, J.B., 2000, Reassessing Discretionary Fiscal Policy, Journal of Economic Perspectives, 14, 21-36.

Woodford, M., 2003, Interest and Prices: Foundations of a Theory of Monetary Policy, Princeton: Princeton University Press.

\section{Appendix}

\subsection{Ramsey problem}

Let $\Gamma$ be the (constant) multiplier on the implementability constraint (18), and let $\lambda_{t}, \psi_{t}$, and $\mu_{t}$ be the (time variable) multipliers on the resource constraint (10), on the definition of the job finding rate (15), and on the labor market equilibrium condition (11), respectively, such that the Lagrangian of the Ramsey problem reads

$$
\begin{aligned}
L= & E_{0} \sum_{t=0}^{\infty} \beta^{t}\left\{\Omega_{t} \frac{c_{t}^{1-\sigma}}{1-\sigma}+\varphi \frac{g_{t}^{1-\gamma}}{1-\gamma}-\chi \frac{n_{t}^{1+\phi}}{1+\phi}\right. \\
+ & +\Gamma\left[\Omega_{t} c_{t}^{-\sigma}\left(-k_{t}+(1-\delta) k_{t-1}+\frac{\varepsilon-1}{\varepsilon}(1-v) a_{t} n_{t}^{v} k_{t-1}^{1-v}\right)\right] \\
+ & \lambda_{t}\left[a_{t} n_{t}^{v} k_{t-1}^{1-v}-c_{t}-b x_{t}^{\alpha+1}\left[1-(1-d) n_{t-1}\right]-g_{t}-k_{t}+(1-\delta) k_{t-1}\right] \\
+ & \psi_{t}\left[x_{t}-\frac{n_{t}-(1-d) n_{t-1}}{1-(1-d) n_{t-1}}\right] \\
+ & \mu_{t}\left[-\frac{\chi c_{t}^{\sigma} n_{t}^{\phi}}{\Omega_{t}}+\frac{\varepsilon-1}{\varepsilon} v a_{t} n_{t}^{v-1} k_{t-1}^{1-v}-(1+\vartheta) b x_{t}^{\alpha}\right. \\
& \left.\left.\quad+\beta b(1-d) \frac{\Omega_{t+1} c_{t+1}^{-\sigma}}{\Omega_{t} c_{t}^{-\sigma}}\left(x_{t+1}^{\alpha}+\left(1-x_{t+1}\right) \vartheta x_{t+1}^{\alpha}\right)\right]\right\} \\
& -\Gamma A_{0} .
\end{aligned}
$$

where $A_{0} \equiv \widetilde{r_{0}} k_{-1} \Omega_{0} c_{0}^{-\sigma}$ (note that (14) does not need to be considered separately, since it is incorporated in (18), and (12) and (13) can be used to determine the capital rate of return $r_{t}$ and the real wage rate $w_{t}$ ).

The optimal Ramsey policy then has to satisfy the following first order conditions with respect to the optimal choice of government spending, consumption, employment, the job finding rate, and capital for $t \geq 1$ :

$$
\frac{\partial L}{\partial g_{t}}=0=\varphi g_{t}^{-\gamma}-\lambda_{t}
$$




$$
\begin{aligned}
& \frac{\partial L}{\partial c_{t}}=0=\Omega_{t} c_{t}^{-\sigma}-\Gamma \sigma \Omega_{t} c_{t}^{-\sigma-1}\left(-k_{t}+(1-\delta) k_{t-1}+\frac{\varepsilon-1}{\varepsilon}(1-v) a_{t} n_{t}^{v} k_{t-1}^{1-v}\right) \\
& -\lambda_{t}-\mu_{t} \sigma \frac{\chi n_{t}^{\phi}}{\Omega_{t}} c_{t}^{\sigma-1}+\mu_{t} \frac{\sigma}{c_{t}} \beta(1-d) b E_{t} \frac{\Omega_{t+1} c_{t}^{\sigma}}{\Omega_{t} c_{t+1}^{\sigma}}\left[x_{t+1}^{\alpha}+\left(1-x_{t+1}\right) \vartheta x_{t+1}^{\alpha}\right] \\
& -\mu_{t-1} \frac{\sigma}{c_{t}}(1-d) b \frac{\Omega_{t} c_{t-1}^{\sigma}}{\Omega_{t-1} c_{t}^{\sigma}}\left[x_{t}^{\alpha}+\left(1-x_{t}\right) \vartheta x_{t}^{\alpha}\right], \\
& \frac{\partial L}{\partial n_{t}}=0=-\chi n_{t}^{\phi}+\Gamma \Omega_{t} c_{t}^{-\sigma} \frac{\varepsilon-1}{\varepsilon} v(1-v) a_{t} n_{t}^{v-1} k_{t-1}^{1-v} \\
& +\lambda_{t} v a_{t} n_{t}^{v-1} k_{t-1}^{1-v}-\psi_{t} \frac{1}{1-(1-d) n_{t-1}} \\
& +\beta E_{t} \lambda_{t+1} b x_{t+1}^{\alpha+1}(1-d)+\beta E_{t} \psi_{t+1} \frac{(1-d)\left(1-x_{t+1}\right)}{1-(1-d) n_{t}} \\
& -\mu_{t} \phi \frac{\chi c_{t}^{\sigma} n_{t}^{\phi-1}}{\Omega_{t}}+\mu_{t} v(v-1) \frac{\varepsilon-1}{\varepsilon} a_{t} n_{t}^{v-2} k_{t-1}^{1-v}, \\
& \frac{\partial L}{\partial x_{t}}=0=-(\alpha+1) \lambda_{t} b x_{t}^{\alpha}\left[1-(1-d) n_{t-1}\right]+\psi_{t}-\mu_{t} \alpha(1+\vartheta) b x_{t}^{\alpha-1} \\
& +\mu_{t-1} b(1-d) \frac{\Omega_{t} c_{t-1}^{\sigma}}{\Omega_{t-1} c_{t}^{\sigma}} x_{t}^{\alpha-1}\left(\alpha(1+\vartheta)-(1+\alpha) \vartheta x_{t}\right) \\
& \frac{\partial L}{\partial k_{t}}=0=-\lambda_{t}+\beta E_{t} \lambda_{t+1}\left[(1-v) a_{t+1} n_{t+1}^{v} k_{t}^{-v}+1-\delta\right]+\beta E_{t} \mu_{t+1} v(1-v) \frac{\varepsilon-1}{\varepsilon} a_{t+1} n_{t+1}^{v-1} k_{t}^{-v} \\
& -\Gamma \Omega_{t} c_{t}^{-\sigma}+\beta \Gamma E_{t} \Omega_{t+1} c_{t+1}^{-\sigma}\left(1-\delta+\frac{\varepsilon-1}{\varepsilon}(1-v)^{2} a_{t+1} n_{t+1}^{v} k_{t}^{-v}\right)
\end{aligned}
$$

together with (10), (15), (11), and (18).

\subsection{Deterministic steady state of the Ramsey allocation}

Suppose that a deterministic steady state exists. In what follows we summarize the properties which the steady state has to satisfy and compute the steady state value numerically. Constant steady state values of variables are denoted by dropping the time subindex. The steady state values of the stochastic shocks are normalized to equal one. From the Ramsey planner's first order conditions and the constraints, the following 9 conditions for $\{c, g, n, k, \Gamma, \lambda, \psi, \mu, x\}$ characterize the steady state:

$$
0=\varphi g^{-\gamma}-\lambda
$$




$$
\begin{aligned}
& 0=c^{-\sigma}-\Gamma \sigma c^{-\sigma-1}\left(-\delta k+\frac{\varepsilon-1}{\varepsilon}(1-v) n^{v} k^{1-v}\right) \\
& -\lambda-\mu \sigma \chi c^{\sigma-1}+\mu \frac{\sigma}{c}(\beta-1)(1-d) b\left[x^{\alpha}+(1-x) \vartheta x^{\alpha}\right], \\
& 0=-\chi n^{\phi}+\Gamma c^{-\sigma} \frac{\varepsilon-1}{\varepsilon} v(1-v) n^{v-1} k^{1-v} \\
& +\lambda v n^{v-1} k^{1-v}-\psi \frac{1}{1-(1-d) n} \\
& +\beta \lambda b x^{\alpha+1}(1-d)+\beta \psi \frac{(1-d)(1-x)}{1-(1-d) n} \\
& -\mu \phi \chi c^{\sigma} n^{\phi-1}+\mu v(v-1) \frac{\varepsilon-1}{\varepsilon} n^{v-2} k^{1-v}, \\
& 0=-(\alpha+1) \lambda b x^{\alpha}[1-(1-d) n]+\psi \\
& -\mu \alpha(1+\vartheta) b x^{\alpha-1} \\
& +\mu b(1-d) x^{\alpha-1}(\alpha(1+\vartheta)-(1+\alpha) \vartheta x), \\
& 0=-\lambda+\beta \lambda\left[(1-v) n^{v} k^{-v}+1-\delta\right]+\beta \mu v(1-v) \frac{\varepsilon-1}{\varepsilon} n^{v-1} k^{-v} \\
& -\Gamma c^{-\sigma}+\beta \Gamma c^{-\sigma}\left(1-\delta+\frac{\varepsilon-1}{\varepsilon}(1-v)^{2} n^{v} k^{-v}\right), \\
& n^{v} k^{1-v}=c+b x^{\alpha} d n+g+\delta k, \\
& \chi c^{\sigma}=\frac{\varepsilon-1}{\varepsilon} v n^{v-1} k^{1-v}-(1+\vartheta) b x^{\alpha}+\beta b(1-d)\left(x^{\alpha}+(1-x) \vartheta x^{\alpha}\right),
\end{aligned}
$$

as well as

$$
x=\frac{d n}{1-(1-d) n}
$$

and the implementability constraint (18); assuming that we are initially in the steady state, $k_{-1}=k$, this reads $(1+r-\delta) k=\frac{1}{1-\beta}\left(-\delta k+\frac{\varepsilon-1}{\varepsilon}(1-v) n^{v} k^{1-v}\right)$, and by using $r=\frac{\varepsilon-1}{\varepsilon}(1-v) n^{v} k^{1-v}$ from the steady state version of 12) it reduces to

$$
1 / \beta=\frac{\varepsilon-1}{\varepsilon}(1-v) n^{v} k^{-v}+1-\delta
$$

which equals the steady state version of a consumption Euler equation. 


\subsection{Welfare comparison}

Denote welfare by $v_{t}$, given by

$$
v_{t}=E_{0} \sum_{t=0}^{\infty} \beta^{t} u\left(c_{t}, n_{t}, g_{t}\right)
$$

or $v_{t}=u\left(c_{t}, n_{t}, g_{t}\right)+\beta E_{t} v_{t+1}$. Denote welfare under the Ramsey policy as

$$
v_{t}^{R}=E_{0} \sum_{t=0}^{\infty} \beta^{t} u\left(c_{t}^{R}, n_{t}^{R}, g_{t}^{R}\right)
$$

and under an alternative regime studied for comparison as

$$
v_{t}^{A}=E_{0} \sum_{t=0}^{\infty} \beta^{t} u\left(c_{t}^{A}, n_{t}^{A}, g_{t}^{A}\right) .
$$

Let the constants $\bar{c}^{R}$ and $\bar{c}^{A}$ be the permanent consumption streams that yield $v_{t}^{R}$ and $v_{t}^{A}$, respectively:

$$
\begin{aligned}
& \sum_{t=0}^{\infty} \beta^{t} \frac{\left(\bar{c}^{R}\right)^{1-\sigma}}{1-\sigma}=v_{t}^{R} \Leftrightarrow \bar{c}^{R}=\left[(1-\beta)(1-\sigma) v_{t}^{R}\right]^{1 /(1-\sigma)}, \\
& \sum_{t=0}^{\infty} \beta^{t} \frac{\left(\bar{c}^{A}\right)^{1-\sigma}}{1-\sigma}=v_{t}^{A} \Leftrightarrow \bar{c}^{A}=\left[(1-\beta)(1-\sigma) v_{t}^{A}\right]^{1 /(1-\sigma)},
\end{aligned}
$$

which for $\sigma=1$ becomes $\bar{c}^{R}=\exp \left[(1-\beta) v_{t}^{R}\right]$ and $\bar{c}^{A}=\exp \left[(1-\beta) v_{t}^{A}\right]$, respectively.

We then measure the consumption equivalent of the welfare loss from the alternative policy relatively to the Ramsey policy by computing

$$
100 \cdot\left(1-\bar{c}^{A} / \bar{c}^{R}\right)
$$

which gives the per cent loss of steady state consumption that is equivalent to the relative utility loss that households would suffer by a permanent switch from the Ramsey to the alternative policy. 


\subsection{Price stickiness}

\subsubsection{Firms}

Firms are assumed to maximize the expected discounted sum of real period profits $q$,

$$
\max E_{t} \sum_{s=0}^{\infty} \phi_{t, t+s} q_{i t+s}
$$

with $q_{i t+s}=\frac{P_{i t+s} y_{i t+s}-P_{t+s} w_{t+s} n_{i t+s}-P_{t+s} r_{t+s} k_{i t+s-1}-P_{t+s} z_{t+s} h_{i t+s}-P_{t+s} \frac{\kappa}{2}\left(\frac{P_{i t+s}}{P_{i t+s-1}}-1\right)^{2}}{P_{t+s}}$,

and $\kappa>0$, subject to $y_{i t+s}=a_{t+s} n_{i t+s}^{v} k_{i t+s-1}^{1-v}, y_{i t+s}=\left(\frac{P_{i t+s}}{P_{t+s}}\right)^{-\varepsilon} y_{t+s}$, and $h_{i t+s}=$ $n_{i t+s}-(1-d) n_{i t+s-1}$, taking the general price level, the real wage and capital rental rate, and firm-level costs per hire $z_{t+s}$ as well as $n_{i,-1}$ and $k_{i,-1}$ as given.

Inserting the production function, we can form a Lagrangian with the demand constraint attached via the multiplier $\Psi_{i t}$ and the hiring constraint via multiplier $\Theta_{i t}$ :

$$
\begin{aligned}
\mathcal{L}_{t}= & E_{t} \sum_{s=0}^{\infty} \phi_{t, t+s}\left\{\left[\frac{P_{i t+s}}{P_{t+s}} a_{t+s} n_{i t+s}^{v} k_{i t+s-1}^{1-v}-w_{t+s} n_{i t+s}-r_{t+s} k_{i t+s-1}-\frac{\kappa}{2}\left(\frac{P_{i t+s}}{P_{i t+s-1}}-1\right)^{2}\right.\right. \\
& \left.-z_{t+s} h_{t+s}+\Theta_{i t+s}\left(h_{i t+s}-n_{i t+s}+(1-d) n_{i t+s-1}\right)\right] \\
& \left.+\Psi_{i t+s}\left[\left(\frac{P_{i t+s}}{P_{t+s}}\right)^{-\varepsilon} y_{t+s}-a_{t+s} n_{i t+s}^{v} k_{i t+s-1}^{1-v}\right]\right\}
\end{aligned}
$$

The first order conditions are

$$
\begin{aligned}
& \frac{\partial \mathcal{L}_{t}}{\partial n_{i t}}=0 \Leftrightarrow \Theta_{i t}=\left(\frac{P_{i t}}{P_{t}}-\Psi_{i t}\right) v a_{t} n_{i t}^{v-1} k_{i t-1}^{1-v}-w_{t}+(1-d) E_{t} \beta \frac{\Omega_{t+1} c_{t+1}^{-\sigma}}{\Omega_{t} c_{t}^{-\sigma}} \Theta_{i t+1}, \\
& \frac{\partial \mathcal{L}_{t}}{\partial h_{i t}}=0 \Leftrightarrow z_{t}=\Theta_{i t}, \\
& \frac{\partial \mathcal{L}_{t}}{\partial k_{i t}}=0 \Leftrightarrow r_{t}=\left[\frac{P_{i t}}{P_{t}}-\Psi_{i t}\right](1-v) a_{t} n_{i t}^{v} k_{i t-1}^{-v}, \\
& \frac{\partial \mathcal{L}_{t}}{\partial P_{i t}}=0 \Leftrightarrow a_{t} n_{i t}^{v} k_{i t-1}^{1-v}\left(\frac{1}{P_{t}}-\varepsilon \Psi_{i t} \frac{1}{P_{i t}}\right)=\kappa\left(\frac{P_{i t}}{P_{i t-1}}-1\right) \frac{1}{P_{i t-1}} \\
&-E_{t} \beta \frac{\Omega_{t+1} c_{t+1}^{-\sigma}}{\Omega_{t} c_{t}^{-\sigma}} \kappa\left(\frac{P_{i t+1}}{P_{i t}}-1\right)\left(\frac{P_{i t+1}}{P_{i t}^{2}}\right) .
\end{aligned}
$$

Under symmetry, applying the definition of the inflation rate $\pi_{t}=P_{t} / P_{t-1}$, and eliminating 
the multipliers leads to

$$
\begin{aligned}
w_{t}= & \frac{\varepsilon-1}{\varepsilon} v a_{t} n_{t}^{v-1} k_{t-1}^{1-v}-b x_{t}^{\alpha}+\beta E_{t} \frac{\Omega_{t+1} c_{t+1}^{-\sigma}}{\Omega_{t} c_{t}^{-\sigma}} b(1-d) x_{t+1}^{\alpha}+\frac{1}{n_{t}} \frac{v}{\varepsilon} \kappa\left(\pi_{t}-1\right) \pi_{t} \\
& -\frac{1}{n_{t}} \frac{v}{\varepsilon} \beta E_{t} \frac{\Omega_{t+1} c_{t+1}^{-\sigma}}{\Omega_{t} c_{t}^{-\sigma}} \kappa\left(\pi_{t+1}-1\right) \pi_{t+1} \\
r_{t}= & \frac{\varepsilon-1}{\varepsilon}(1-v) a_{t} n_{t}^{v} k_{t-1}^{-v}+\frac{1-v}{\varepsilon k_{t-1}} \kappa\left(\pi_{t}-1\right) \pi_{t}-\frac{1-v}{\varepsilon k_{t-1}} \beta E_{t} \frac{\Omega_{t+1} c_{t+1}^{-\sigma}}{\Omega_{t} c_{t}^{-\sigma}} \kappa\left(\pi_{t+1}-1\right) \pi_{t+1},
\end{aligned}
$$

where the equilibrium relation for hiring costs $z_{t}=b x_{t}^{\alpha}$ have been substituted; symmetric profits are

$$
q_{t}=y_{t}-w_{t} n_{t}-r_{t} k_{t-1}-z_{t} h_{t}-\frac{\kappa}{2}\left(\pi_{t}-1\right)^{2} .
$$

The wage bargaining problem is unaltered, and the bargained wage is again given by (6).

\subsubsection{Rational expectations equilibrium}

For any given fiscal and monetary policy the rational expectations equilibrium is characterized by

$$
\begin{aligned}
a_{t} n_{t}^{v} k_{t-1}^{1-v}= & c_{t}+b x_{t}^{\alpha}\left[n_{t}-(1-d) n_{t-1}\right]+g_{t}+k_{t}-(1-\delta) k_{t-1}+\frac{\kappa}{2}\left(\pi_{t}-1\right)^{2} \\
\frac{\chi c_{t}^{\sigma} n_{t}^{\phi}}{\Omega_{t}}= & \frac{\varepsilon-1}{\varepsilon} v a_{t} n_{t}^{v-1} k_{t-1}^{1-v}-(1+\vartheta) b x_{t}^{\alpha}+\beta b(1-d) E_{t} \frac{\Omega_{t+1} c_{t+1}^{-\sigma}}{\Omega_{t} c_{t}^{-\sigma}}\left[x_{t+1}^{\alpha}+\left(1-x_{t+1}\right) \vartheta x_{t+1}^{\alpha}\right] \\
& +\frac{1}{n_{t}} \frac{v}{\varepsilon} \kappa\left(\pi_{t}-1\right) \pi_{t}-\frac{1}{n_{t}} \frac{v}{\varepsilon} \beta E_{t} \frac{\Omega_{t+1} c_{t+1}^{-\sigma}}{\Omega_{t} c_{t}^{-\sigma}} \kappa\left(\pi_{t+1}-1\right) \pi_{t+1} \\
r_{t}= & \frac{\varepsilon-1}{\varepsilon}(1-v) a_{t} n_{t}^{v} k_{t-1}^{-v}+\frac{1-v}{\varepsilon k_{t-1}} \kappa\left(\pi_{t}-1\right) \pi_{t}-\frac{1-v}{\varepsilon k_{t-1}} \beta E_{t} \frac{\Omega_{t+1} c_{t+1}^{-\sigma}}{\Omega_{t} c_{t}^{-\sigma}} \kappa\left(\pi_{t+1}-1\right) \pi(41) \\
w_{t}= & \frac{\varepsilon-1}{\varepsilon} v a_{t} n_{t}^{v-1} k_{t-1}^{1-v}-b x_{t}^{\alpha}+\beta E_{t} \frac{\Omega_{t+1} c_{t+1}^{-\sigma}}{\Omega_{t} c_{t}^{-\sigma}} b(1-d) x_{t+1}^{\alpha}+\frac{1}{n_{t}} \frac{v}{\varepsilon} \kappa\left(\pi_{t}-1\right) \pi_{t} \\
& -\frac{1}{n_{t}} \frac{v}{\varepsilon} \beta E_{t} \frac{\Omega_{t+1} c_{t+1}^{-\sigma}}{\Omega_{t} c_{t}^{-\sigma}} \kappa\left(\pi_{t+1}-1\right) \pi_{t+1} \\
\Omega_{t} c_{t}^{-\sigma}= & \beta E_{t} \Omega_{t+1} c_{t+1}^{-\sigma}\left[r_{t+1}+1-\delta\right] \\
\Omega_{t} c_{t}^{-\sigma}= & \beta E_{t} \Omega_{t+1} c_{t+1}^{-\sigma} R_{t} \\
x_{t}= & \frac{n_{t}-(1-d) n_{t-1}}{1-(1-d) n_{t-1}}
\end{aligned}
$$

as well as the transversality condition and initial conditions. We incorporate the transversality condition by constructing an implementability condition, which is slightly different in the case of price stickiness. Starting from (17),

$$
\widetilde{r_{0}} k_{0} \Omega_{0} c_{0}^{-\sigma}=E_{0} \sum_{t=0}^{\infty} \beta^{t} \Omega_{t} c_{t}^{-\sigma}\left(c_{t}-w_{t} n_{t}-q_{t}+g_{t}\right)
$$


and inserting profits, which from (38) and the resource constraint (39) are given by

$$
\begin{aligned}
q_{t} & =y_{t}-w_{t} n_{t}-r_{t} k_{t-1}-z_{t} h_{t}-\frac{\kappa}{2}\left(\pi_{t}-1\right)^{2} \\
& =c_{t}+g_{t}+k_{t}-\left(1+r_{t}-\delta\right) k_{t-1}-w_{t} n_{t}
\end{aligned}
$$

(so the price adjustment cost term cancels), yields

$$
\begin{aligned}
\widetilde{r_{0}} k_{0} \Omega_{0} c_{0}^{-\sigma}= & E_{0} \sum_{t=0}^{\infty} \beta^{t} \Omega_{t} c_{t}^{-\sigma}\left(-k_{t}+\left(1+r_{t}-\delta\right) k_{t-1}\right) \\
= & E_{0} \sum_{t=0}^{\infty} \beta^{t} \Omega_{t} c_{t}^{-\sigma}\left\{-k_{t}+\left(1+\left[\frac{\varepsilon-1}{\varepsilon}(1-v) a_{t} n_{t}^{v} k_{t-1}^{-v}+\frac{(1-v)}{\varepsilon k_{t-1}} \kappa\left(\pi_{t}-1\right) \pi_{t}\right.\right.\right. \\
& \left.\left.\left.-\frac{(1-v)}{\varepsilon k_{t-1}} \beta \frac{\Omega_{t+1} c_{t+1}^{-\sigma}}{\Omega_{t} c_{t}^{-\sigma}} \kappa\left(\pi_{t+1}-1\right) \pi_{t+1}\right]-\delta\right) k_{t-1}\right\},
\end{aligned}
$$

where the second equality replaces $r_{t}$ with the respective private sector equilibrium condition from (41).

\subsubsection{Ramsey problem}

The Lagrangian for this problem reads as follows. Note, first that (43) does not need to be considered, since it is incorporated in (47), and (41) just residually defines the capital rate of return $r_{t}$, which is not needed here, while the labor demand condition (42) just residually defines $w_{t}$, which is also not needed here. Second, equation (44) residually defines the nominal bond interest rate $R_{t}$, which is the instrument of monetary policy, such that we need not carry (44) as a separate constraint either. Thus, the policy maker's Lagrangian is

$$
\begin{aligned}
& L=E_{0} \sum_{t=0}^{\infty} \beta^{t}\left\{\Omega_{t} \frac{c_{t}^{1-\sigma}}{1-\sigma}+\varphi \frac{g_{t}^{1-\gamma}}{1-\gamma}-\chi \frac{n_{t}^{1+\phi}}{1+\phi}\right. \\
& +\Gamma\left[\Omega_{t} c_{t}^{-\sigma}\left(\begin{array}{c}
-k_{t}+(1-\delta) k_{t-1}+\frac{\varepsilon-1}{\varepsilon}(1-v) a_{t} n_{t}^{v} k_{t-1}^{1-v}+\frac{(1-v)}{\varepsilon} \kappa\left(\pi_{t}-1\right) \pi_{t} \\
-\frac{(1-v)}{\varepsilon} \beta \frac{\Omega_{t+1} c_{t+1}^{-\sigma}}{\Omega_{t} c_{t}^{-\sigma}} \kappa\left(\pi_{t+1}-1\right) \pi_{t+1}
\end{array}\right)\right] \\
& +\lambda_{t}\left[a_{t} n_{t}^{v} k_{t-1}^{1-v}-c_{t}-b x_{t}^{\alpha+1}\left[1-(1-d) n_{t-1}\right]-g_{t}-k_{t}+(1-\delta) k_{t-1}-\frac{\kappa}{2}\left(\pi_{t}-1\right)^{2}\right] \\
& +\psi_{t}\left[x_{t}-\frac{n_{t}-(1-d) n_{t-1}}{1-(1-d) n_{t-1}}\right] \\
& \left.+\mu_{t}\left[\begin{array}{c}
-\frac{\chi c_{t}^{\sigma} n_{t}^{\phi}}{\Omega_{t}}+\frac{\varepsilon-1}{\varepsilon} v a_{t} n_{t}^{v-1} k_{t-1}^{1-v}-(1+\vartheta) b x_{t}^{\alpha} \\
+\beta b(1-d) \frac{\Omega_{t+1} c_{t+1}^{-\sigma}}{\Omega_{t} c_{t}^{-\sigma}}\left[x_{t+1}^{\alpha}+\left(1-x_{t+1}\right) \vartheta x_{t+1}^{\alpha}\right]+\frac{1}{n_{t}} \frac{v}{\varepsilon} \kappa\left(\pi_{t}-1\right) \pi_{t} \\
-\frac{1}{n_{t}} \frac{v}{\varepsilon} \beta \frac{\Omega_{t+1} c_{t+1}^{-\sigma}}{\Omega_{t} c_{t}^{-\sigma}} \kappa\left(\pi_{t+1}-1\right) \pi_{t+1}
\end{array}\right]\right\} \\
& -\Gamma A_{0} \text {. }
\end{aligned}
$$


The first order conditions for the periods $t \geq 1$ are

$$
0=\varphi g_{t}^{-\gamma}-\lambda_{t},
$$

$$
\begin{aligned}
& 0=\Omega_{t} c_{t}^{-\sigma} \\
& -\Gamma \sigma \Omega_{t} c_{t}^{-\sigma-1}\left(\begin{array}{c}
-k_{t}+(1-\delta) k_{t-1}+\frac{\varepsilon-1}{\varepsilon}(1-v) a_{t} n_{t}^{v} k_{t-1}^{1-v} \\
+\frac{(1-v)}{\varepsilon} \kappa\left(\pi_{t}-1\right) \pi_{t}-\frac{(1-v)}{\varepsilon} \beta \frac{\Omega_{t+1} c_{t+1}^{-\sigma}}{\Omega_{t} c_{t}^{-\sigma}} \kappa\left(\pi_{t+1}-1\right) \pi_{t+1}
\end{array}\right) \\
& -\Gamma \Omega_{t} c_{t}^{-\sigma}\left(\frac{\sigma}{c_{t}} \frac{(1-v)}{\varepsilon} \beta \frac{\Omega_{t+1} c_{t+1}^{-\sigma}}{\Omega_{t} c_{t}^{-\sigma}} \kappa\left(\pi_{t+1}-1\right) \pi_{t+1}\right) \\
& +\Gamma \Omega_{t-1} c_{t-1}^{-\sigma}\left(\frac{\sigma}{c_{t}} \frac{(1-v)}{\varepsilon} \frac{\Omega_{t} c_{t}^{-\sigma}}{\Omega_{t-1} c_{t-1}^{-\sigma}} \kappa\left(\pi_{t}-1\right) \pi_{t}\right) \\
& -\lambda_{t}-\mu_{t} \sigma \frac{\chi n_{t}^{\phi}}{\Omega_{t}} c_{t}^{\sigma-1}+\mu_{t} \frac{\sigma}{c_{t}} \beta(1-d) b E_{t} \frac{\Omega_{t+1} c_{t}^{\sigma}}{\Omega_{t} c_{t+1}^{\sigma}}\left[x_{t+1}^{\alpha}+\left(1-x_{t+1}\right) \vartheta x_{t+1}^{\alpha}\right] \\
& -\mu_{t-1} \frac{\sigma}{c_{t}}(1-d) b \frac{\Omega_{t} c_{t-1}^{\sigma}}{\Omega_{t-1} c_{t}^{\sigma}}\left[x_{t}^{\alpha}+\left(1-x_{t}\right) \vartheta x_{t}^{\alpha}\right] \\
& -\mu_{t} \frac{\sigma}{c_{t}} \frac{1}{n_{t}} \frac{v}{\varepsilon} \beta \frac{\Omega_{t+1} c_{t+1}^{-\sigma}}{\Omega_{t} c_{t}^{-\sigma}} \kappa\left(\pi_{t+1}-1\right) \pi_{t+1}+\mu_{t-1} \frac{\sigma}{c_{t}} \frac{1}{n_{t-1}} \frac{v}{\varepsilon} \frac{\Omega_{t} c_{t}^{-\sigma}}{\Omega_{t-1} c_{t-1}^{-\sigma}} \kappa\left(\pi_{t}-1\right) \pi_{t}, \\
& 0=-\chi n_{t}^{\phi}+\Gamma \Omega_{t} c_{t}^{-\sigma} \frac{\varepsilon-1}{\varepsilon} v(1-v) a_{t} n_{t}^{v-1} k_{t-1}^{1-v} \\
& +\lambda_{t} v a_{t} n_{t}^{v-1} k_{t-1}^{1-v}-\psi_{t} \frac{1}{1-(1-d) n_{t-1}} \\
& +\beta E_{t} \lambda_{t+1} b x_{t+1}^{\alpha+1}(1-d)+\beta E_{t} \psi_{t+1} \frac{(1-d)\left(1-x_{t+1}\right)}{1-(1-d) n_{t}} \\
& -\mu_{t} \phi \frac{\chi c_{t}^{\sigma} n_{t}^{\phi-1}}{\Omega_{t}}+\mu_{t} v(v-1) \frac{\varepsilon-1}{\varepsilon} a_{t} n_{t}^{v-2} k_{t-1}^{1-v} \\
& -\mu_{t} \frac{1}{n_{t}^{2}} \frac{v}{\varepsilon}\left[\kappa\left(\pi_{t}-1\right) \pi_{t}-\beta \frac{\Omega_{t+1} c_{t+1}^{-\sigma}}{\Omega_{t} c_{t}^{-\sigma}} \kappa\left(\pi_{t+1}-1\right) \pi_{t+1}\right], \\
& 0=-(\alpha+1) \lambda_{t} b x_{t}^{\alpha}\left[1-(1-d) n_{t-1}\right]+\psi_{t}-\mu_{t} \alpha(1+\vartheta) b x_{t}^{\alpha-1} \\
& +\mu_{t-1} b(1-d) \frac{\Omega_{t} c_{t-1}^{\sigma}}{\Omega_{t-1} c_{t}^{\sigma}} x_{t}^{\alpha-1}\left(\alpha(1+\vartheta)-(1+\alpha) \vartheta x_{t}\right), \\
& 0=-\lambda_{t}+\beta E_{t} \lambda_{t+1}\left[(1-v) a_{t+1} n_{t+1}^{v} k_{t}^{-v}+1-\delta\right]+\beta E_{t} \mu_{t+1} v(1-v) \frac{\varepsilon-1}{\varepsilon} a_{t+1} n_{t+1}^{v-1} k_{t}^{-v} \\
& -\Gamma \Omega_{t} c_{t}^{-\sigma}+\Gamma E_{t} \Omega_{t+1} c_{t+1}^{-\sigma}\left(1-\delta+\frac{\varepsilon-1}{\varepsilon}(1-v)^{2} a_{t+1} n_{t+1}^{v} k_{t}^{-v}\right),
\end{aligned}
$$




$$
0=-\lambda_{t} \kappa\left(\pi_{t}-1\right)+\left(\kappa\left(\pi_{t}-1\right)+\kappa \pi_{t}\right)\left[\mu_{t} \frac{v}{\varepsilon n_{t}}+\Gamma \Omega_{t} c_{t}^{-\sigma} \frac{1-v}{\varepsilon}-\left(\frac{\Omega_{t} c_{t-1}^{\sigma}}{\Omega_{t-1} c_{t}^{\sigma}} \mu_{t-1} \frac{v}{\varepsilon n_{t-1}}+\Gamma \Omega_{t-1} c_{t-1}^{-\sigma} \frac{1-v}{\varepsilon}\right)\right]
$$
together with (39), (45), (40), and (47). 


\section{Tinbergen Institute}

The Tinbergen Institute is the institute for economic research of the Erasmus Universiteit Rotterdam, Universiteit van Amsterdam, and Vrije Universiteit Amsterdam.

Tinbergen Institute Amsterdam

Roetersstraat 31

1018 WB Amsterdam

The Netherlands

Tel.: $\quad+31(0) 205513500$

Fax: $\quad+31(0) 205513555$

Tinbergen Institute Rotterdam

Burg. Oudlaan 50

3062 PA Rotterdam

The Netherlands

Tel.: $\quad+31(0) 104088900$

Fax: $\quad+31(0) 104089031$

Most TI discussion papers can be downloaded at http:/ /www.tinbergen.nl. 